Département de sciences économiques

2005-02

Economic Development under Alternative Trade Regimes

CASTRO, Rui 


\section{Département de sciences économiques}

Université de Montréal

Faculté des arts et des sciences

C.P. 6128, succursale Centre-Ville

Montréal (Québec) H3C 3J7

Canada

http://www.sceco.umontreal.ca

SCECO-information@UMontreal.CA

Téléphone : (514) 343-6539

Télécopieur : (514) 343-7221

Ce cahier a également été publié par le Centre interuniversitaire de recherche en économie quantitative (CIREQ) sous le numéro 01-2005.

This working paper was also published by the Center for Interuniversity Research in Quantitative Economics (CIREQ), under number 01-2005.

ISSN 0709-9231 


\title{
Economic Development under Alternative Trade Regimes*
}

\author{
Rui Castro \\ Department of Economics and CIREQ, Université de Montréal
}

August 2004

\begin{abstract}
How does openness affect economic development? This question is answered in the context of a dynamic general equilibrium model of the world economy, where countries have technological differences that are both sector-neutral and specific to the investment goods sector. Relative to a benchmark case of trade in credit markets only, consider (i) a complete restriction of trade, and (ii) a full liberalization of trade. The first change decreases the cross-sectional dispersion of incomes only slightly, and produces a relatively small welfare loss. The second change, instead, decreases dispersion by a significant amount, and produces a very large welfare gain. (JEL E13, F43, O11, O30)
\end{abstract}

Keywords: Economic Development, International Trade, Investment-Specific Technology, Quantitative Dynamic General Equilibrium, Incomplete Markets.

*Université de Montréal, Département de Sciences Économiques, C.P. 6128, succ. Centre-Ville, Montréal (Québec), Canada H3C 3J7. I wish to thank the editor, José-Víctor Ríos-Rull, as well as two anonymous referees, for very detailed and helpful comments. Thanks also to Per Krusell for his guidance and many helpful suggestions, and to Rui Albuquerque, Daniele Coen-Pirani, Jeremy Greenwood, and seminar participants at McGill University, Michigan State University, Universidade de Aveiro, Université de Montréal, Federal Reserve Bank of Dallas, 2000 Rochester Wegmans conference, 2001 meetings of the Society for Economic Dynamics in Stockholm, 2002 North American Summer meetings of the Econometric Society in Los Angeles, 2002 CMSG meetings in Kingston, and 2003 Federal Reserve Bank of Cleveland Conference on Trade, Capital Flows and Aggregate Dynamics. All remaining errors are mine. Financial support from Praxis XXI is gratefully acknowledged. Email: rui.castro@umontreal.ca. Web: http://www.fas.umontreal.ca/sceco/castroru. 


\section{Introduction}

This paper is a quantitative study of the consequences for economic development and growth of alternative international trade arrangements. The main objective is to analyze and quantify the effects on both efficiency (average world income and welfare) and inequality (cross-sectional dispersion in world incomes and distributional welfare effects).

The starting point (benchmark trade arrangement) is a basic model of an integrated world economy featuring a large number of small open economies, each producing a single homogeneous consumption good and a single homogeneous investment good. Consumption goods are nontradable, and therefore countries are prevented from intratemporally trading capital goods for consumption goods. As a consequence, domestic investment prices relative to consumption prices reflect the relative consumption-investment sectoral productivities. Countries may still engage in intertemporal trade. Financial markets, however, are complete at the national level but incomplete at the worldwide level. International borrowing and lending is freely allowed through trade in one-period noncontingent bonds, as long as a country's net foreign debt does not violate a borrowing constraint. National economies are ex-ante identical, but sector-neutral productivity and the productivity of the investment goods sector are stochastic. Both technology shocks are purely country-specific. In part because these risks are uninsurable in world financial markets, national economies will be different ex-post. The model generates time-invariant equilibrium cross-sectional distributions of development variables, namely GDP per worker, which can be compared with the data. The basic setup can be seen as combining Clarida (1990), Huggett (1993) and Aiyagari's (1994) models of heterogeneous agents with Greenwood, Hercowitz, and Krusell's (1997) model of investment-specific technical change.

In the benchmark model of the world economy, part of the cross-country differences in technology are specific to investment goods. This suggests that trading capital goods for consumption goods should be an important way for technological improvements to diffuse internationally. The data, however, clearly suggests that countries do not benefit to the full extent from this potentially important channel.

Recent evidence by Eaton and Kortum (2001), on the one hand, documents the importance of both home bias and regionalism for trade in capital goods. On average, for a cross-section of 34 developing and developed countries in 1985, nearly half of total domestic investment in equipment comes from domestic production. And when equipment is in fact traded it appears that geography, in the sense of physical and cultural proximity, plays an important role. Eaton and Kortum (2001)

find that barriers to trade in capital goods do have to be very important quantitatively in order to account for observed trade flows in equipment.

On the other hand, and perhaps more importantly, there is also complementary evidence sug- 
gesting that investment goods are not traded enough precisely in exchange for consumption goods. In particular, De Long and Summers (1991), Jones (1994) and much subsequent work has shown that the international dispersion in the relative price of equipment is large, and strongly negatively associated with incomes. Figure 1, which is based on data for 110 countries from the Penn World Tables (version 6.1) described in Heston, Summers, and Aten (2002), shows a similar negative association using aggregate investment prices relative to aggregate consumption prices.

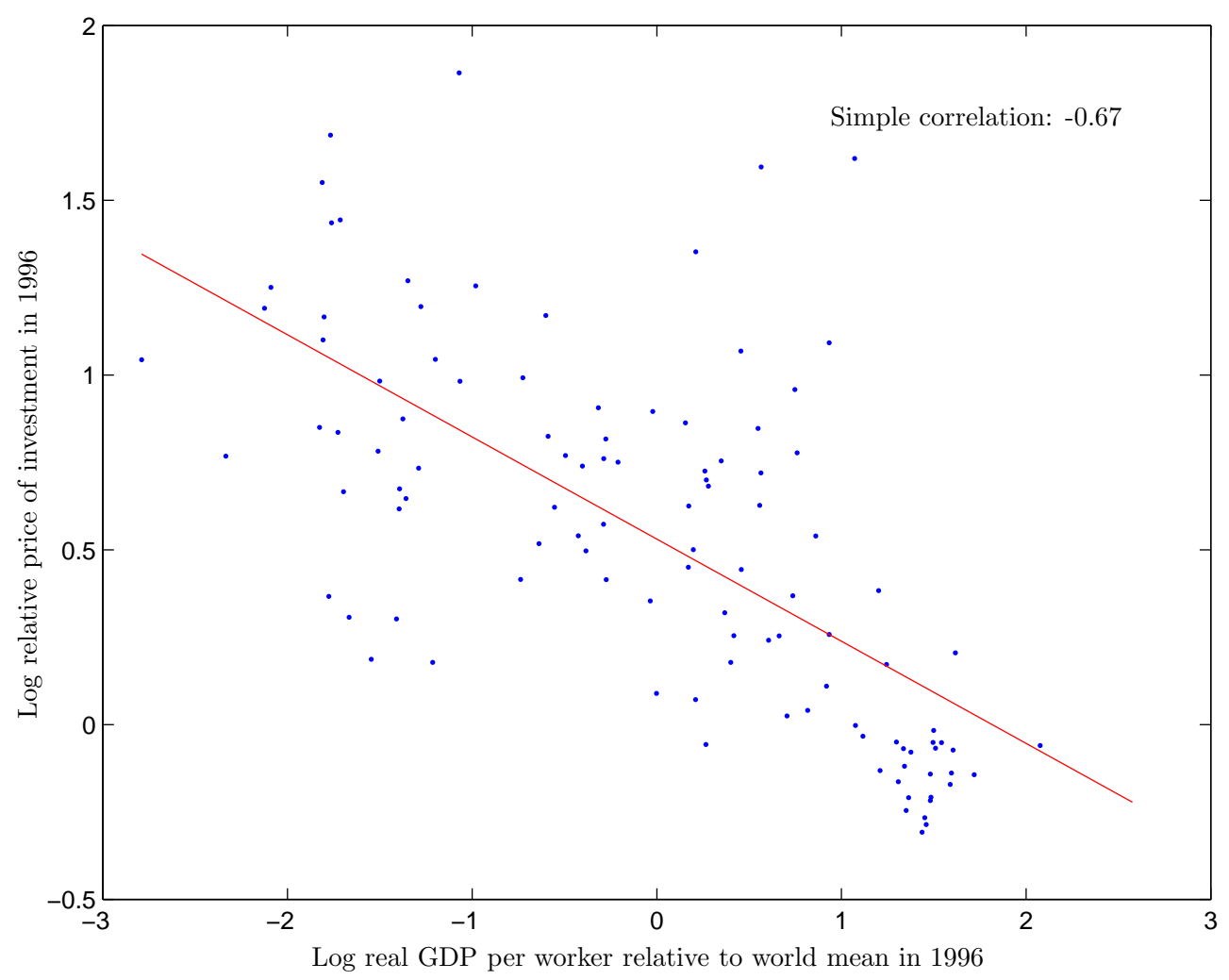

Figure 1: Investment Prices and World Incomes

Figure 1 begs a natural question: what would the consequences for economic development be if barriers to international trade between investment and consumption goods were eliminated? Eliminating barriers would entail improving the tradability of investment goods per se and, perhaps even more importantly, improving the tradability of consumption goods as well. In other words, policies should be aimed at reducing the worldwide dispersion in relative, not just absolute, investment prices. This way, countries with relatively inefficient investment sectors should be able to import most of their capital needs, while specializing in producing and exporting consumption goods. One may conjecture that, following this regime change, the distribution of relative incomes underlying Figure 1 should become less dispersed (the effect on inequality), and the associated distribution of absolute incomes should shift to the right (the effect on efficiency). 
This question is related to some of the recent literature in economic development, namely recent work by Eaton and Kortum (2001) and Hsieh and Klenow (2003). Both papers can be seen as pointing to the potential importance of eliminating barriers to intratemporal trade in different goods. Hsieh and Klenow (2003) trace many important development regularities back to crosscountry differences in relative consumption-investment sectoral productivities. In their work, like in this paper's benchmark model, large relative productivity differences coexist with large relative price differences, which requires some degree of trade impediments. Eaton and Kortum (2001), as pointed out previously, obtain quantitative measures of impediments to trade in equipment, and find them to be large. Reducing these impediments is an obvious way poor countries may use comparative advantage to benefit from the superior technology of rich countries. The approach of this paper is to take observed relative productivity differences as given, and to consider the complete elimination of all impediments to trade. As a natural starting point, this paper abstracts from the potential direct effect that reducing trade impediments might have on the distribution of productivities. Naturally, not all barriers may be eliminated in practice. Hence, this exercise should be interpreted as providing an informative upper bound for the potential effects.

To answer the question, and to get an idea of the magnitudes, I consider a modification of the baseline trade arrangement whereby countries may trade freely capital goods for consumption goods. All remaining features of the original setup are held constant. In particular, labor is still immobile internationally. In equilibrium, trade is of the Ricardian type, with countries specializing completely in production at each point in time according to their comparative advantage determined by technology.

This paper also studies a second change in the world trade arrangement, that of eliminating world credit markets and thus moving into autarky. This helps shed some light on whether it is intertemporal trade in the same physical good, or intratemporal trade in different goods, that matters the most for economic development. This is an important question: policymakers often point to the inability to borrow from abroad in order to invest domestically as one main obstacle to economic development. As before, the only change in the benchmark setup is in the international trade arrangement. The resulting world economy becomes a collection of closed economies, and in this sense bears important similarities to the one studied by Chari, Kehoe, and McGrattan (1997) and Restuccia and Urrutia (2001).

Regarding the effect on inequality, the results point to a significant decline in world income dispersion following a complete liberalization of trade. Since returns to capital are equalized internationally, both in consumption and in investment units, capital-output ratios become essentially identical across countries. As a consequence, the model predicts a long-run reduction of world income inequality of about 7.4 percent. It turns out, however, that going from the benchmark trade arrangement to autarky also reduces the international dispersion in capital-output ratios and 
incomes. Countries that are more efficient at producing capital goods invest more but, for closed economies, the larger domestic investment must be matched by larger domestic saving. A higher domestic real interest rate is required to entice higher saving, which in turn discourages investment and capital accumulation. If economies are open, instead, foreign resources can be used along with domestic saving in investing, generating a larger effect on capital. Due to this leveraging via international borrowing, a given degree of international dispersion in the relative efficiency of capital goods production leads to a larger international dispersion in incomes when economies are open rather than when they are closed. I conclude in particular that long-run income dispersion would be reduced by about 1.3 percent if world credit markets were eliminated. These findings suggest that the effect of openness on world income inequality should depend crucially on the specific changes being made on the international trade arrangement. By providing well-defined concepts of openness, which are based upon changes in the worldwide trade arrangement, the present setting should be particularly helpful in addressing this question. If openness means liberalization of financial markets, then world income inequality should increase slightly. If, instead, openness means liberalization of goods' markets, then world income inequality would be significantly reduced. For less stylized changes in openness, with elements of both financial market and goods market liberalization, the effect on inequality may well be ambiguous.

The results on efficiency and welfare are quite striking. Quantitatively, while shutting-down financial markets would produce a relatively small average welfare loss, equivalent to a 2 percent decrease in steady-state consumption, fully liberalizing trade in goods would have a very large average welfare gain, equivalent to a 35 percent increase in steady-state consumption. A substantial part of this large welfare improvement arises from static production specialization gains, and therefore is not all compensated by lower transitional welfare gains. With transitional effects explicitly taken into account, the overall welfare gain is still equivalent to a very significant 25 percent increase in consumption. I also find important distributional welfare effects. Welfare improvements are substantially larger for currently poorer countries. They are also larger for countries with high relative investment prices and low capital-output ratios, that is, for countries that are particularly inefficient at producing capital goods.

In a world with significant investment-specific technical differences, liberalizing intratemporal trade in goods at the worldwide level seems to be particularly important in raising living standards. Financial market liberalization alone is a poor substitute at best. A tentative policy implication from this paper's results is that more effort should be concentrated in promoting free trade in goods and not so much in promoting full or improved access to world credit markets, as is sometimes the emphasis of institutions like the International Monetary Fund or the World Bank. ${ }^{1}$

\footnotetext{
${ }^{1}$ Many authors endorse the view that international financial flows are potentially very important in the long-run. For a recent example see Summers (2000).
} 
This paper is organized as follows. Section 2 describes the model and defines the equilibrium. Section 3 analyzes the setup with free mobility of capital. Section 4 briefly describes the solution method. Section 5 discusses measurement and calibration issues. Section 6 presents the main results and discusses some limitations of the analysis, and Section 7 concludes. The Appendix contains some details on the data set, on the numerical procedure, and on the potential role of transportation costs.

\section{Model World Economies}

I consider a world economy composed of a continuum of small open economies with unit measure, each potentially producing two goods: a single homogeneous consumption good and a single homogeneous investment good. All consumers have identical preferences. All firms have access to the state-of-the-art technology but, due to country-specific factors, firms in different countries may end up using different technologies.

Part of the country-specific differences in technology are sector-neutral, i.e. they are common to both sectors of production. An important component of the differences in technology, instead,

is specific to the production of investment goods. I next describe various versions of a model world economy, where individual countries are subject to these two sources of technological differences, and which differ only in terms of the international trade arrangement.

\subsection{Environment}

I start by describing the assumptions on preferences, technology, and the different market arrangements. To save on notation, I omit country subscripts.

\section{Preferences}

Each individual consumer has preferences defined over streams of consumption given by

$$
\mathrm{E}_{0} \sum_{t=0}^{\infty} \beta^{t} u\left(C_{t}\right) .
$$

Leisure is not valued and individuals will inelastically supply their total time endowment of one unit to market activities.

\section{Technology}

Each national economy may produce a single consumption good $Y^{c}$ according to

$$
Y_{t}^{c}=A_{z t} F\left(K_{t}^{c}, N_{t}^{c}\right),
$$

and a single investment good $Y^{i}$ according to

$$
Y_{t}^{i}=\left(A_{z t} / A_{\theta t}\right) F\left(K_{t}^{i}, N_{t}^{i}\right)
$$


where $F$ is a neoclassical national production function satisfying all the usual properties. The sectorial inputs, stock of physical capital and labor input (total man-hours employed), must add up to the total quantities available in each country, so that

$$
\begin{aligned}
K_{t}^{d} & =K_{t}^{c}+K_{t}^{i} \\
N_{t} & =N_{t}^{c}+N_{t}^{i},
\end{aligned}
$$

where $K_{t}^{d}$ is the domestic capital stock, employed in period t's production. The labor force grows exogenously at a constant rate which is the same for all countries. Both inputs to production are perfectly mobile across sectors at the national level.

The technological parameters are defined by $A_{z t}=z_{t} X_{z t}$ and $A_{\theta t}=\theta_{t} X_{\theta t}$, where the pair $\left(X_{z t}, X_{\theta t}\right)$ is deterministic and common to all countries, representing the state of the world technology frontier at time $t$, and the pair $\left(z_{t}, \theta_{t}\right)$ is a stochastic transitory component of technology, which is country-specific. The deterministic components of technology grow exogenously at constant rates. Instead, the country-specific components follow a joint stationary first-order Markov process described by:

$$
\mathbf{s}_{t+1}=\boldsymbol{\mu}+\boldsymbol{\Gamma} \mathbf{s}_{t}+\varepsilon_{t+1}
$$

where $\mathbf{s}_{t} \equiv\left(\ln z_{t}, \ln \theta_{t}\right)^{\top}$ and $\varepsilon_{t+1}$ is a vector of innovations. The elements determining the transition, that is $\boldsymbol{\mu}, \boldsymbol{\Gamma}$ and the stochastic process for the innovations, are homogenous across countries, and a law of large numbers is assumed to hold in the cross-section. Countries are ex-ante identical, and differ only ex-post, to the extent that their shock histories also differ. In other words, there is no ex-ante heterogeneity across countries.

The view implicit in this formulation is that all countries may potentially benefit from the world technology frontier at all times. At a point in time, however, different countries perform differently relative to the world frontier. This may be due to various factors, such as Parente and Prescott's (2002) idea of obstacles to technology adoption. These factors are represented by $\mathbf{s}_{t}$, and they are not modelled explicitly. This paper's exercise will be to ask, given these factors, how important different trade arrangements can be for economic development.

Gross domestic output in consumption units, or real GDP in the model, is defined by

$$
Y_{t}=Y_{t}^{c}+P_{t} Y_{t}^{i}
$$

where $P_{t}$ is the relative price of investment goods in terms of consumption goods in a given country at time $t$. Output can be consumed, invested, or transferred to foreigners, in the amount $T B_{t}$, according to a nationwide resource constraint

$$
Y_{t}=C_{t}+P_{t} I_{t}+T B_{t}
$$


where $P_{t} I_{t}$ are the net purchases of investment goods and $T B_{t}$ is the trade balance, both measured in terms of $C_{t}$. Physical capital depreciates geometrically at rate $\delta \in[0,1]$. The capital stock owned by residents, denoted by $K_{t}$, evolves according to

$$
K_{t+1}=I_{t}+(1-\delta) K_{t}
$$

Depending on the market arrangement considered, $K_{t}$ and $K_{t}^{d}$ may differ. That is, residents may not own all of their domestic capital stock, or they may own part of other countries' capital stocks. ${ }^{2}$

\section{Markets}

I consider three different market arrangements in the world economy: benchmark trade, free trade, and no trade. The benchmark trade arrangement features free trade in financial assets and capital goods. Free trade is the benchmark trade arrangement with the addition of trade in consumption goods, and no trade corresponds to autarky. In the reminder of the paper, I will abbreviate benchmark trade by BT, free trade by FT, and no trade by NT.

Financial markets are complete at the national level but incomplete at the worldwide level. In particular, the set of international financial assets is restricted exogenously to a one period riskless bond denominated in terms of consumption. International borrowing and lending is freely allowed at the world interest rate $r_{t+1}$, as long as countries do not violate a borrowing constraint. Labor is always immobile internationally, so that countries are defined by the location of their labor input.

I now describe in more detail the assumptions underlying each trade regime, starting with free trade, since the remaining two regimes may be obtained by imposing certain particular restrictions on free trade.

Under the free trade (FT) arrangement, both consumption goods and capital goods are freely tradable. Physical capital can thus be freely traded intratemporally for consumption goods. I make an admittedly extreme assumption regarding the mobility of physical capital within each period. I assume it can be traded in either one of two markets. First, it can be traded on an ex-ante market. That is, before next period's technology is revealed, a competitive market opens up for buying and selling units of capital at price $P_{t}$. Newly-produced capital, in particular, is traded only in this market, due to some form of "time to build." There is thus a symmetry between domesticallyproduced new capital goods and new capital goods purchased in world markets, in that decisions involving either of them are made under uncertainty about future production conditions. Second, capital can also be traded ex-post. That is, after uncertainty is resolved, there is a competitive worldwide rental market for all capital that has been produced up to that moment, paying a gross

\footnotetext{
${ }^{2}$ One may find it useful to notice that the trade balance should equal total net exports, measured in consumption units. Hence, one could write $T B_{t}=X_{t}^{c}+P_{t} X_{t}^{i}$, where $X_{t}^{c}=Y_{t}^{c}-C_{t}$ and $X_{t}^{i}=Y_{t}^{i}-I_{t}$ are the net exports of consumption and investment goods, respectively. In turn, through the balance-of-payments identity, $T B_{t}$ should equal the current account less the net factor income from abroad. In what follows, $T B_{t}$ is defined in terms of this counterpart. The specific form it takes will depend on the market arrangement considered.
} 
return of $\hat{R}_{t}$ units of consumption per unit of capital rented. Throughout the paper I refer to the ex-post market as the "market for old capital goods." 3

The domestic capital stock, that is, the capital stock employed in domestic production, can thus be decomposed as

$$
K_{t}^{d}=K_{t}-K_{t}^{T}
$$

where $K_{t}$ is the component owned by residents, and $K_{t}^{T}$ corresponds to net exports, in the form of rentals, of physical capital services. The resident-owned net addition to the domestic capital stock may come partially from producing new capital goods and partially from buying new capital goods in world markets. It is equivalent, however, to think of all countries that produce investment goods as first selling all their production, and then purchasing their desired $I_{t}$ in world markets. This way $I_{t}$ corresponds to total purchases, and $Y_{t}^{i}$ to total sales, of new capital goods at time $t$ for any given country. ${ }^{4}$ Domestic investment in this setup may be defined accordingly as

$$
I_{t}^{d}=K_{t+1}^{d}-(1-\delta) K_{t}^{d}
$$

For clarity, Figure 2 provides a summary of the timing under free trade. Period $t$ begins with a new technology pair. With this information, firms decide how much capital to use in production this period, by renting capital services in world markets. They may thus complement the resident-owned capital stock carried over from period $t-1$. Production takes place with the domestic capital stock $K_{t}^{d}$. Next, payments on beginning-of-period net foreign bond holdings $\left(B_{t}\right)$ and current-period capital rentals are carried out. Finally, agents decide how much to consume, how much to save in the form of foreign bonds, and how much physical capital to buy or sell in the world market for new capital goods.

Countries must own positive amounts of physical capital and are thus unable to borrow in the world market for new capital, so that

$$
K_{t} \geq 0
$$

and I also assume that, in the world market for old capital, countries can rent capital services only

\footnotetext{
${ }^{3}$ Capital can thus be installed in the period of its use in production. A more standard arrangement would allow for trade in the ex-ante market only. It turns out, however, that its quantitative implications are almost identical to those under FT - these results are available upon request. This is not very surprising: what ex-post capital rentals allow is for countries to trade away ex-post differences in returns induced by differences in realized capital-output ratios. In this model, however, very little heterogeneity in capital-output ratios remains if heterogeneity in $A_{\theta t}$ plays no role, as it will be the case under FT. The analysis would become significantly more complicated under this more standard arrangement, since there would be no simple arbitrage condition linking the world price of capital and the real world interest rate. Section 3 demonstrates that, due precisely to this arbitrage condition, the model under FT may be recast in a much simpler way, which will be critical to the computation of the transition to the free trade regime. Ex-post trade in capital is thus assumed mainly for simplicity, and it does not have any significant effect on the quantitative results.

${ }^{4}$ Throughout the paper I refer to the ex-ante market as the market for new capital even though $I_{t}<0$ is possible, which means that a country would be selling old capital units in the ex-ante market.
} 


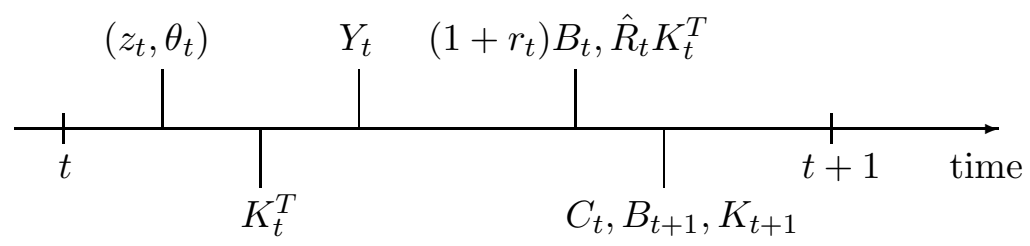

Figure 2: Timing under Free Trade

up to the capital stock owned by residents, or

$$
K_{t}^{T} \leq K_{t}
$$

The trade balance records all transactions between residents and foreigners and is given by

$$
T B_{t}=B_{t+1}-\left(1+r_{t}\right) B_{t}-\left[\hat{R}_{t}-(1-\delta) P_{t}\right] K_{t}^{T},
$$

where the last term is the net inflow of resources associated with capital rentals decided at the end of last period (part of the the net factor income from abroad), with the component in square brackets being the world rental price of capital.

The constraint on international borrowing takes the form

$$
B_{t+1} \geq \underline{B}\left(\Omega_{t}, z_{t}, \theta_{t}\right),
$$

where $\underline{B}\left(\Omega_{t}, z_{t}, \theta_{t}\right)$ denotes the minimum net asset level allowed. The constraint (3) may be due to informational and commitment problems, but I will not be explicit about them. In anticipation of the recursive formulation of the country's problem of Section 2.3, the limit on borrowing is restricted to be a function of the current state $\left(\Omega_{t}, z_{t}, \theta_{t}\right)$, where $\Omega_{t}$ denotes the total amount of resources available for domestic consumption, or a country's wealth in period $t$ :

$$
\Omega_{t} \equiv Y_{t}+(1-\delta) P_{t} K_{t}+\left[\hat{R}_{t}-(1-\delta) P_{t}\right] K_{t}^{T}+\left(1+r_{t}\right) B_{t}
$$

Under the benchmark trade (BT) arrangement, only capital goods are tradable, ${ }^{5}$ so that $K_{t}^{T}=0$ and $P_{t}=A_{\theta t}$ for all $t$. This means that there are no intratemporal trades across countries, only intertemporal trades. I analyze this setup in more detail in a companion paper, Castro (2004).

\footnotetext{
${ }^{5}$ The results in this paper do not depend upon which of the two goods, capital or consumption, is nontradable. With one of them nontradable, intratemporal trades between goods are not possible, and relative investment prices reflect relative sectoral productivities. I emphasize nontradable consumption for the sake of realism, since most capital goods, equipment in particular, are traded more than most consumption goods. Hsieh and Klenow (2003) also take this view. As pointed out by Eaton and Kortum (2001) and Hsieh and Klenow (2003), in this extreme case, absolute investment prices (i.e., expressed in terms of some numeraire currency) are equalized internationally, but relative investment prices are higher in countries with relatively inefficient investment sectors (analogous to the Balassa-Samuelson effect). As in the main text, relative investment prices reflect relative consumption-investment sectoral productivities. This same result would arise if the nontradable good was instead capital. The choice of the nontradable good would only have consequences for cross-country differences in absolute investment and consumption prices.
} 
Finally, under no trade (NT), there are neither intratemporal nor intertemporal trades, so that all countries live in autarky. Hence, it is still the case that $K_{t}^{T}=0$ and $P_{t}=A_{\theta t}$ for all $t,{ }^{6}$ but now also $B_{t}=0$ for all $t$. This arrangement shares some similarities with Chari, Kehoe, and McGrattan (1997) and Restuccia and Urrutia (2001). In particular, the world economy becomes a collection of closed economies that do not interact with one another.

Individuals are homogeneous within each country, even if potentially subject to purely idiosyncratic uncertainty. Since domestic financial markets are complete one may focus on the planner's problem at the national level, equipped with the preferences and technology described above. The resulting allocation at the national level can be decentralized by various schemes (see for example Stokey, Lucas, and Prescott, 1989).

\subsection{Model Specification}

The specification of preferences and technology is standard and obeys the restrictions required for balanced growth to be possible. Momentary utility is described by a isoelastic function

$$
u\left(C_{t}\right)=\frac{C_{t}^{1-\sigma}}{1-\sigma}
$$

where $\sigma>0$ is the coefficient of relative risk aversion (if $\sigma=1$ then momentary utility is logarithmic).

Production in both sectors is done according to the same Cobb-Douglas production function, common to all countries

$$
F\left(K_{t}^{j}, N_{t}^{j}\right)=\left(K_{t}^{j}\right)^{\alpha}\left(N_{t}^{j}\right)^{1-\alpha} \quad \text { for } j=i, c
$$

where $0<\alpha<1$ is the share of physical capital. The deterministic components of technology grow at rates $X_{z t+1} / X_{z t}=\gamma_{z}^{1-\alpha}$ and $X_{\theta t+1} / X_{\theta t}=\gamma_{\theta}^{-1}$, with $\gamma_{z}, \gamma_{\theta} \geq 1$. The labor force grows at rate $\gamma_{n} \geq 1$. In the long-run, output and consumption in particular will grow at rate $\gamma \equiv \gamma_{n} \gamma_{z} \gamma_{\theta}^{\alpha /(1-\alpha)}$. Finite utility requires $\beta \gamma^{1-\sigma}<1$, which holds by assumption. Variables are normalized so that $N_{0}=X_{z 0}=X_{\theta 0}=1$.

The borrowing constraint is assumed to be

$$
\underline{B}\left(\Omega_{t}, z_{t}, \theta_{t}\right)=-\eta \Omega_{t},
$$

so that a national economy is able to borrow only up to a multiple $\eta \geq 0$ of current resources. ${ }^{7}$

\footnotetext{
${ }^{6}$ Under perfect competition, with free mobility of factors across sectors and $F$ CRS, it is easy to show that under both BT and NT a single aggregate resource constraint can be written as $A_{z t} F\left(K_{t}^{d}, N_{t}\right)=C_{t}+P_{t} I_{t}^{d}+T B_{t}$, with $P_{t}=A_{\theta t}$ being the autarkic price of investment. There are no intratemporal trades in this case. This aggregation is possible since cost minimization requires employing the same capital-labor intensity across sectors, equal to the aggregate intensity.

${ }^{7}$ Suppose that, due to implicit informational and commitment problems, lenders require countries to finance at
} 
The technology shocks follow a vector autoregressive (VAR) process of order one in logs. In particular, in the transition equation (1):

$$
\boldsymbol{\mu}=\left(\begin{array}{c}
\mu_{z} \\
\mu_{\theta}
\end{array}\right), \quad \boldsymbol{\Gamma}=\left(\begin{array}{cc}
\rho_{z z} & \rho_{z \theta} \\
\rho_{\theta z} & \rho_{\theta \theta}
\end{array}\right)
$$

and $\boldsymbol{\varepsilon}_{t}^{\top} \equiv\left(\varepsilon_{z t}, \varepsilon_{\theta t}\right)$ is a vector of innovations which is i.i.d. $N(\mathbf{0}, \boldsymbol{\Sigma})$ with

$$
\boldsymbol{\Sigma}=\left(\begin{array}{cc}
\sigma_{z}^{2} & \sigma_{z \theta} \\
\sigma_{z \theta} & \sigma_{\theta}^{2}
\end{array}\right)
$$

This parsimonious specification choice is dictated by the need to simplify the solution of the model. It also turns out to be sufficiently flexible, in the sense that it is able to capture the key empirical features of cross-sectional distribution of productivities, in particular it is able to match quantitatively the cross-country dispersion in measured productivity indexes. This is discussed in more detail in Section 5.

\subsection{Equilibrium}

I study the stationary recursive competitive equilibrium of the world economy under each of the three trade arrangements. All variables are appropriately transformed in terms of efficiency units of labor, so that they remain constant over time in the nonstochastic steady-state of the model, and are denoted with lower-case letters. We then have $\lambda_{t}=\Lambda_{t} / \gamma^{t}$ for $\Lambda_{t}=C_{t}, B_{t}, Y_{t}, Y_{t}^{c}$ and $\Omega_{t}$, and $\lambda_{t}=\Lambda_{t} /\left(\gamma \gamma_{\theta}\right)^{t}$ for $\Lambda_{t}=Y_{t}^{i}, K_{t}^{d}, K_{t}^{T}, K_{t}, I_{t}^{d}$ and $I_{t}$. Detrended world prices are denoted by $p_{t}=\gamma_{\theta}^{t} P_{t}$ and $R_{t}=\gamma_{\theta}^{t} \hat{R}_{t}$. The country's state space is $S \equiv \Omega \times Z \times \Theta=\mathbb{R}_{+}^{3}$. In what follows I denote with primes next-period variables and without primes current-period variables.

In the FT arrangement, countries will specialize completely in the production of either consumption or investment goods at a point in time, according to whether $p<\theta$ or $p \geq \theta$, respectively, and where $\theta$ corresponds to the (detrended) relative price of capital under autarky. ${ }^{8}$ Incorporating this specialization decision, production for an economy under FT becomes

$$
y=\max \{1, p / \theta\} z\left(k-k_{T}\right)^{\alpha}
$$

That is, countries specialize completely in production, and depending on the path of $\theta$ we may have drastic changes in comparative advantage over time. Since technology turn out to be very persistent, these changes will not happen often though.

least a fraction $0 \leq \kappa \leq 1$ of their current total ex-ante period $t$ expenditures (those potentially subject to financial frictions) out of current domestic resources, so that $\kappa\left(C_{t}+P_{t} K_{t+1}\right) \leq \Omega_{t}$. Using the resource constraint to substitute for $C_{t}$ this can be written as in (6) with $\eta \equiv(1-\kappa) / \kappa \geq 0$. The parameter $\kappa$ is equivalent to the margin requirement in Aiyagari and Gertler (1999). The constraint (6) is a tractable reduced form of a more explicit setup capturing the basic feature that richer countries are able to borrow more. Finally, note that $C_{t}, K_{t+1} \geq 0$ imply $\Omega_{t} \geq 0$.

${ }^{8}$ By assumption, countries with $p=\theta$ will specialize completely in the production of investment goods. At the cost of increased complexity, would could in principle introduce heterogeneity in goods as a way to avoiding complete specialization in production. In a related setting, Eaton and Kortum (2001) explore some of the implications of heterogeneity in capital goods. 
I next define a competitive equilibrium under FT. The corresponding definitions under BT and NT are particular cases, namely they can be obtained by setting $p=\theta$ and $k_{T}=0(\mathrm{BT})$, and $p=\theta$, $k_{T}=0$ and $b=0(\mathrm{NT})$.

Definition A stationary recursive competitive equilibrium for the world economy under free trade is a value function $v(\omega, \mathbf{s})$, a set of decision rules $c(\omega, \mathbf{s}), b^{\prime}(\omega, \mathbf{s}), k^{\prime}(\omega, \mathbf{s})$ and $k_{T}^{\prime}\left(\omega, \mathbf{s} ; \mathbf{s}^{\prime}\right)$, a cross-sectional distribution of countries $\psi$ over individual states $(\omega, \mathbf{s})$ and world prices $r, p$ and $R$ such that:

1. Given $r, p$ and $R$, the decision rules $c(\omega, \mathbf{s}), b^{\prime}(\omega, \mathbf{s}), k^{\prime}(\omega, \mathbf{s})$ and $k_{T}^{\prime}\left(\omega, \mathbf{s} ; \mathbf{s}^{\prime}\right)$ solve the country's problem and $v(\omega, \mathbf{s})$ is the corresponding value function, that is, for all $(\omega, \mathbf{s}) \in S$ :

$$
v(\omega, \mathbf{s})=\max _{c, b^{\prime}, k^{\prime}}\left\{u(c)+\beta \gamma^{1-\sigma} \mathrm{E}_{\mathbf{s}} \max _{k_{T}^{\prime}} v\left(\omega^{\prime}, \mathbf{s}^{\prime}\right)\right\}
$$

subject to

$$
\begin{aligned}
\gamma\left(\gamma_{\theta} p k^{\prime}+b^{\prime}\right)+c & \leq \omega \\
\omega^{\prime} & \equiv y^{\prime}+[R-(1-\delta) p] k_{T}^{\prime}+(1-\delta) p k^{\prime}+(1+r) b^{\prime} \\
y^{\prime} & \equiv \max \left\{1, p / \theta^{\prime}\right\} z^{\prime}\left(k^{\prime}-k_{T}^{\prime}\right)^{\alpha} \\
\gamma b^{\prime} & \geq-\eta \omega \\
c & \geq 0, k^{\prime} \geq 0, k^{\prime} \geq k_{T}^{\prime} \\
\mathbf{s}^{\prime} & =\boldsymbol{\mu}+\boldsymbol{\Gamma} \mathbf{s}+\boldsymbol{\varepsilon}^{\prime} \\
b_{0} & =0 ; \mathbf{s}_{0}, k_{0}>0 \text { given. }
\end{aligned}
$$

2. The world foreign bond market clears:

$$
\int_{S} b^{\prime}(\omega, \mathbf{s}) d \psi=0
$$

The world market for old capital clears:

$$
\int_{S \times S} k_{T}^{\prime}\left(\omega, \mathbf{s} ; \mathbf{s}^{\prime}\right) d \psi d \psi^{\prime}=0 .
$$

The world market for new capital clears:

$$
\int_{S} y^{i}\left(\omega^{\prime}, \mathbf{s}^{\prime}\right) d \psi^{\prime}=\int_{S \times S} i\left(\omega, \mathbf{s}, \omega^{\prime}, \mathbf{s}^{\prime}\right) d \psi d \psi^{\prime} .
$$

3. The distribution of countries is stationary and consistent with countries' behavior:

$$
\psi(\hat{S})=\int_{S} P(x, \hat{S}) d \psi(x) \quad \text { for all } \hat{S} \in \mathcal{B}_{S},
$$

where $P: S \times \mathcal{B}_{S} \rightarrow[0,1]$ is a transition function, induced by the decision rules and by the stochastic process for $\mathbf{s}$, and $\mathcal{B}_{S}$ is the Borel $\sigma$-algebra of subsets of $S$. 


\section{Free Trade Arrangement in the Long-Run}

One useful property of the FT arrangement is that it is possible to recast it in terms of a problem similar to the one studied in Clarida (1990). That is, the world under FT is analogous to a world of endowment economies, subject to idiosyncratic shocks to their endowments and with access to international borrowing and lending and a higher bound on national debt.

Too see this, notice that the first-order conditions to the problem defined in Section 2.3 yield:

$$
\begin{aligned}
\left(k_{T}^{\prime}\right) & : \quad R=\frac{\alpha y^{\prime}}{k^{\prime}-k_{T}^{\prime}}+p(1-\delta) \\
\left(k^{\prime}\right): & \gamma_{\theta} p \geq \beta \gamma^{-\sigma} \mathrm{E}_{\mathbf{s}}\left[\frac{u^{\prime}\left(c^{\prime}\right)}{u^{\prime}(c)} R\right] \quad \text { with }=\text { if } k^{\prime}>0 \\
\left(b^{\prime}\right): & (1+r)^{-1} \geq \beta \gamma^{-\sigma} \mathrm{E}_{\mathbf{s}}\left[\frac{u^{\prime}\left(c^{\prime}\right)}{u^{\prime}(c)}\right] \quad \text { with }=\text { if } \gamma b^{\prime}>-\eta \omega,
\end{aligned}
$$

implying for an unconstrained economy

$$
\gamma_{\theta} p(1+r)=R
$$

Since unconstrained economies will have a positive measure in equilibrium, world prices must satisfy (10). Equation (10) reflects the fact that new capital and foreign bonds are perfect substitutes as stores of value, and that new and old capital are perfect substitutes in production. Moreover, the existence of a competitive world market for renting old capital means that old capital must earn the world return everywhere, which is fixed. As a consequence, this framework does not provide sharp predictions, neither for the composition of saving, nor for the composition of domestic capital at the country level.

Substituting equation (10) in the first-order condition for $k_{T}^{\prime}$ implies that at all times and for all countries, given $k^{\prime}, k_{T}^{\prime}$ will adjust so that

$$
\begin{aligned}
k_{T}^{\prime} & =k^{\prime}-\left[\frac{\alpha z^{\prime} \max \left\{1, p / \theta^{\prime}\right\}}{p\left(\gamma_{\theta}(1+r)-1+\delta\right)}\right]^{1 /(1-\alpha)} \\
& \equiv k^{\prime}-k^{d}\left(\mathbf{s}^{\prime}\right)
\end{aligned}
$$

From (11) it follows that $k^{d}(\mathbf{s}) / y=\alpha /\left[p\left(\gamma_{\theta}(1+r)-1+\delta\right)\right]$. Free mobility of old capital is crucial here, since it eliminates any cross-sectional or temporal dispersion in domestic capital-output ratios. Naturally, both expected and realized returns to capital will be equalized as well.

This feature makes it possible to simplify the problem dramatically. Using (11), one can recast the country's problem in terms of choosing simply between consumption and saving, the latter being defined by

$$
x^{\prime} \equiv \gamma_{\theta} p k^{\prime}+b^{\prime}
$$


That is, the country's problem can now be stated as:

$$
v(\omega, \mathbf{s})=\max _{c, x^{\prime}}\left\{u(c)+\beta \gamma^{1-\sigma} \mathrm{E}_{\mathbf{s}} v\left(\omega^{\prime}, \mathbf{s}^{\prime}\right)\right\}
$$

subject to

$$
\begin{aligned}
\omega & \geq c+\gamma x^{\prime} \\
\omega^{\prime} & \equiv e\left(\mathbf{s}^{\prime}\right)+(1+r) x^{\prime} \\
e\left(\mathbf{s}^{\prime}\right) & \equiv(1-\alpha)\left[p\left(\gamma_{\theta}(1+r)-1+\delta\right) / \alpha\right]^{\alpha /(\alpha-1)}\left[z^{\prime} \max \left\{1, p / \theta^{\prime}\right\}\right]^{1 /(1-\alpha)} \\
\gamma x^{\prime} & \geq-\eta \omega,
\end{aligned}
$$

and as part of the solution we obtain the decision rule $x^{\prime}(\omega, \mathbf{s})$. The split of $x^{\prime}$ between $\gamma_{\theta} p k^{\prime}$ and $b^{\prime}$ is arbitrary from the country's perspective, since capital and bonds are perfect substitutes in channelling saving. Hence, only the cross-sectional distribution of total saving will matter for the equilibrium, not the cross-sectional distributions of capital or net foreign bonds individually.

The form of the borrowing constraint is originally $\gamma b^{\prime} \geq-\eta \omega$ and $k^{\prime} \geq 0$. However, since countries are indifferent between saving in the form of capital or foreign bonds, if they have the possibility of avoiding any of the two borrowing constraints by adjusting their portfolio composition they will always choose not to be constrained. ${ }^{9}$ The relevant borrowing constraint thus applies to $x^{\prime}$.

The problem above is simply that of a country subject to a random endowment and with access to trade in noncontingent bonds in order to smooth out the fluctuations in income. This is essentially the problem studied in Clarida (1990) or in Huggett (1993), the main difference being in the market clearing condition. It is important to notice, however, that it is precisely by solving for all three world prices and then using (11) that one is able to derive implications for variables related to capital accumulation in an "endowment economies" model.

For this reformulation of the problem, the world prices $r$ and $p$ must ensure equilibrium in the market for old capital, which simplifies to ${ }^{10}$

$$
\int_{S} k^{d}(\mathbf{s}) d \psi=\int_{S} k^{\prime}(\omega, \mathbf{s}) d \psi,
$$

and equilibrium in the market for new capital, which becomes

$$
\int_{S} \frac{z}{\theta} k^{d}(\mathbf{s})^{\alpha} I_{\{p \geq \theta\}} d \psi=\left(\gamma \gamma_{\theta}-1+\delta\right) \int_{S} k^{d}(\mathbf{s}) d \psi
$$

\footnotetext{
${ }^{9}$ That is, as long as the multiplier associated with any of the two borrowing constraints is not zero a country will not choose to be constrained in one of the assets and not the other. Otherwise, by simply changing its portfolio composition, a country would be able to strictly increase lifetime utility at no cost.

${ }^{10}$ Since there is no uncertainty at the worldwide level, aggregate world quantities are time-invariant.
} 
where $I_{\{p \geq \theta\}}$ is an indicator function that takes value 1 if $p \geq \theta$ and 0 otherwise. It turns out that equation (14) can be solved explicitly for $r$ as a function of $p$ :

$$
r=\frac{1}{\gamma_{\theta}}\left[\frac{\alpha\left(\gamma \gamma_{\theta}-1+\delta\right) \int_{S}(z / p)^{1 /(1-\alpha)} I_{\{p<\theta\}} d \psi}{\int_{S}(z / \theta)^{1 /(1-\alpha)} I_{\{p \geq \theta\}} d \psi}\right]+\frac{1}{\gamma_{\theta}}\left[\alpha\left(\gamma \gamma_{\theta}-1\right)-(1-\alpha) \delta+1\right]-1
$$

From the equilibrium condition in the market for foreign bonds (9), together with equations (12) and (13), we also obtain a single condition in terms of saving:

$$
\int_{S} x^{\prime}(\omega, \mathbf{s}) d \psi=\gamma_{\theta} p \int_{S} k^{d}(\mathbf{s}) d \psi
$$

The model's equilibrium prices will be the values of $r, p$ and $R$ that satisfy equations (10), (15) and (16). This system can be solved recursively, and it is further simplified from the fact that only equation (16) depends directly on decisions.

\section{Solution Method}

A closed-form solution for the steady-state of any of the three model world economies is not available and therefore I use numerical methods. In this section I briefly describe the main steps of the procedure, which is similar across trade arrangements - see Castro (2004) for further details. Under BT, the main step of the algorithm finds the real world interest rate that clears the world bond market. Under FT, the main step finds the world relative price of investment that clears the market for new capital, as described by equation (16), with the real interest rate being given exactly by equation (15) at each stage.

For given world prices, I solve an individual country's problem by value function iteration, using nonlinear continuous approximation methods. The Bellman equation holds on a finite grid for the state-space. I then use Gaussian quadrature to compute the conditional expectation on the righthand-side of the Bellman equation and three-dimensional cubic spline interpolation to evaluate the value function at states outside the grid. Once the equilibrium decision rules have been solved for, I compute the optimal decisions on a much finer grid. The market outcome associated with given world prices is computed by simulating the problem of an individual country for a large number of periods, where decisions at states outside the grid are found by simple linear interpolation.

\section{Measurement and Calibration}

The relevant data set is a panel of 110 countries from 1961 to 1996, a subset of the Penn World Table (PWT), version 6.1, described in Heston, Summers, and Aten (2002). This panel is selected in order to maximize the number of countries and years with complete information on both incomes and investment. I next describe the main elements of the measurement and calibration procedure. Appendix A.1 and Castro (2004) contain further details. 
Regarding the measurement of productivity indexes, one first issue concerns the trends $\gamma_{z}$ and $\gamma_{\theta}$. Since the PWT does not provide a direct way to identify the latter, and since different values for $\gamma_{\theta}$ do not tend to have a significant effect on this paper's results, I assume $\gamma_{\theta}=1$. In the quantitative analysis, all growth is therefore due to growth in $X_{z}$.

A second issue is the measurement of the country-specific components $\theta$ and $z$. The $\theta$ 's could in principle be identified directly from the relative investment price data, that is from $P I^{p w t} / P C^{p w t}$, where $P I^{p w t}$ and $P C^{p w t}$ are the PWT data for the domestic price levels of investment and consumption, respectively. ${ }^{11}$ These relative price series, however, turn out to be fairly noisy for some countries, suggesting the existence of measurement error that could introduce a downward bias on the persistence of technological indexes. I therefore start by filtering the raw series, in order to reduce the measurement error. ${ }^{12}$ The resulting smoothed series $(P I / P C)^{s m}$ correspond to the "true" underlying panel actually used to identify $\theta$.

In order to measure the $z$ shocks, and consistently with the nationwide resource constraint, it is necessary to concentrate on output measured in consumption units, using domestic prices. In practice, this may be achieved by adjusting PPP incomes from the PWT, so that investment expenditures are measured in terms of consumption units, using domestic rather than international prices. To this end, I compute investment expenditures as $(P I / P C)^{s m} I^{p w t}$, where $I^{p w t}$ is the PWT data for PPP-adjusted investment. Based upon this measure of investment, I construct a measure of adjusted output $Y^{a}$ for each country-year pair given by

$$
Y^{a}=Y^{p w t}-\left[1-\left(\frac{P I}{P C}\right)^{s m}\right] I^{p w t},
$$

where $Y^{p w t}$ corresponds to real GDP per worker in PPP terms. This paper's results under any of the three trade arrangements, however, will be expressed in terms output as it is measured in the PWT, i.e. they refer to:

$$
y^{m}=y+(1-\theta) i,
$$

where $y$ and $i$ correspond, respectively, to output and gross investment in the model, both in effective units of labor.

To construct a panel for Solow residuals, I follow the standard approach of relying on a single aggregate Cobb-Douglas production function, and using data on $Y^{a}$ and on the aggregate capital stock per worker to back out $A_{z}^{p w t}$ residually. ${ }^{13}$ The resulting detrended observations $z^{p w t}$ constitute

\footnotetext{
${ }^{11}$ This identification is of course legitimate only under the simplifying assumption that intratemporal trade between investment and consumption is not permitted under BT. Only in this case do relative investment prices reflect relative sectoral productivities. In reality, we do observe such trades in the data but, as discussed in the Introduction, their scope seems to be quite limited. The assumption of nontradable consumption under BT should be regarded as a convenient approximation.

${ }^{12}$ I use a simple exponential filter, with smoothing parameter equal to 0.5 . The motivation to perform this filtering is merely to be on the safe side. The procedure only considers to be measurement error very wild movements in the series from one period to the next. Different filtering procedures tend to produce very similar results. An alternative approach, followed by Restuccia and Urrutia (2001), would be to average observations over some years.

${ }^{13}$ This approach is legitimate given that aggregation obtains under BT, as already discussed in footnote 6 .
} 
measures of $z$. For simplicity I refer to $z$ as Solow residuals, or TFP. Rendering the series stationary is accomplished by removing a linear time trend, common to all countries. This procedure yields a point estimate for $\gamma_{z}$ of 1.02, implying an annual growth rate of TFP of 1.5 percent.

Once the panel for productivity indexes is obtained, the seven parameters of stochastic process are selected so as to approximately equate seven key theoretical moments implied by (1) with the corresponding empirical moments. ${ }^{14}$ Importantly, this ensures that the relevant properties of the distribution of productivity indexes implied by the estimated process resembles reasonably well the empirical counterparts. Table 1 reports the resulting parameters, and $\boldsymbol{\mu}$ is simply normalized to zero in the calibration. ${ }^{15}$

Table 1: VAR Parameters

\begin{tabular}{ccccccc}
\hline$\rho_{z z}$ & $\rho_{z \theta}$ & $\rho_{\theta z}$ & $\rho_{\theta \theta}$ & $\sigma_{z}$ & $\sigma_{\theta}$ & $\sigma_{z \theta}$ \\
\hline 0.995 & -0.014 & -0.001 & 0.980 & 0.052 & 0.096 & 0.003 \\
\hline
\end{tabular}

The remaining parameter values are summarized in Table 2. The depreciation rate is $\delta=0.06$ and the physical capital share is $\alpha=1 / 3$, consistently with independent evidence on income shares. ${ }^{16}$ The parameter $\gamma_{n}$ equals 1.019 , the mean across countries of the average annual growth rate of the labor force, computed from the PWT. The coefficient of relative risk aversion is $\sigma=1.5$, a standard choice in quantitative analysis, and in accordance with many empirical estimates.

Table 2: Benchmark Calibration

\begin{tabular}{cccccccc}
\hline$\beta$ & $\sigma$ & $\delta$ & $\gamma_{z}$ & $\gamma_{\theta}$ & $\gamma_{n}$ & $\alpha$ & $\eta$ \\
\hline 0.983 & 1.5 & 0.06 & 1.02 & 1.0 & 1.019 & $1 / 3$ & 0.37 \\
\hline
\end{tabular}

Following Baxter and Crucini (1995), I select the discount factor to $\beta=0.983$, which approximately equates the equilibrium real world interest rate under BT to 6.5 percent, the postwar U.S. average of the annual real return on capital (see King and Rebelo, 2000). Finally I select $\eta=0.37$, so that the model under BT matches the standard deviation of the trade balance to GDP in the data and thus, in this sense, features a realistic amount of cross-country trade.

\footnotetext{
${ }^{14}$ Specifically, let $\mathbf{V}_{j} \equiv \mathrm{E}\left(\mathbf{s}_{t} \mathbf{s}_{t-j}^{\top}\right)$, for $j=0,1,2$. These theoretical moments may be computed analytically (see Hamilton (1994), pp. 265-266). The seven moments to be matched are the three in $\mathbf{V}_{0}$, plus the two diagonal elements of each of $\mathbf{V}_{1}$ and $\mathbf{V}_{2}$. The parameters in Table 1 approximately equate these moments to their empirical counterparts. Compactly, the empirical counterparts correspond to $(T I)^{-1} \sum_{i, t}\left(x_{i t}-\bar{x}_{t}\right)\left(y_{i t}-\bar{y}_{t}\right)$ and $((T-j) I)^{-1} \sum_{i, t}\left(x_{i t}-\bar{x}_{t}\right)\left(x_{i t-j}-\bar{x}_{t}\right)$, for $x, y \in\{z, \theta\}$, where $\bar{x}_{t}$ and $\bar{y}_{t}$ are the cross-sectional sample means, and $T$ and $I$ are respectively the number of years and countries in the sample.

${ }^{15}$ Similar parameter values obtain if we restrict the sample to countries with frequent benchmark year data, where actual price information was collected, rather than extrapolated. Specifically, this is the case for the subsample of 35 countries with benchmark data in 1980, 1985 and 1996.

${ }^{16}$ The use of a common depreciation rate and capital share for all countries and time periods is also adopted in most development studies, such as Chari, Kehoe, and McGrattan (1997) and Mankiw, Romer, and Weil (1992). Gollin (2002) provides evidence justifying a common capital share, equal to about $1 / 3$, as long as proprietors' income is accounted as labor income.
} 


\section{Findings}

I first describe the experiments. I consider two separate surprise changes in trade restrictions. One moves the world economy from BT to NT (move to autarky), the other from BT to FT (trade liberalization). When liberalizing trade, the upper bound on borrowing is kept constant across BT and FT, so that the only element changing is the tradability of consumption goods. Similarly, when moving to autarky, the only element changing is the degree of access to world credit markets. ${ }^{17}$

The goal of the experiments is to (i) compare the cross-country dispersion in incomes and capital-output ratios across trade regimes, (ii) compare the aggregate world level of income and capital across trade regimes, and (iii) perform a welfare analysis, both in the aggregate and for subsets of countries.

It turns out that trade liberalization produces welfare numbers that, based upon a steadystate comparison, are quite large quantitatively. Hence, for this regime change only, I also report results that incorporate transitional effects. In Section 6.1 I concentrate first on the consequences for inequality, i.e. dispersion in world incomes, and in Section 6.2 I study the consequences for efficiency, i.e. average world incomes and welfare.

The equilibrium prices under FT turn out to be $p=0.63$ and $r=7.3$ percent. The world interest rate is above the one in the BT allocation, 6.5 percent, since foreign bonds under FT have to compete with physical capital as a store of value.

The equilibrium world price of capital goods under FT induces a pattern of specialization in production in the world economy. In the long-run, about 16 percent of the countries (those with $\theta<p$ ) specialize in the production of investment goods, with the remaining 84 percent specializing in the production of consumption goods. The production of investment goods is therefore highly concentrated.

In terms of the long-run cross-sectional distribution of net foreign assets under BT, 31 percent of the economies are constrained in world credit markets. Under FT this number becomes only 0.07 percent, since economies have a multitude of margins along which to trade internationally.

\subsection{Inequality}

The first column of Table 3 reports some summary statistics characterizing the cross-sectional dispersion of the world distributions of real GDP per worker (RY) and capital-output ratios (RKY), both measured relative to the corresponding world (geometric) means, in the data and in the model. The second column computes the predicted change in actual dispersion. In obtaining these numbers, the model's overall change in dispersion is adjusted by the model's initial explanatory

\footnotetext{
${ }^{17}$ It turns out that under BT the borrowing constraint binds for just under $1 / 3$ of the countries in the long-run. Therefore, eliminating financial flows will in fact provide a good idea of the importance of trade in credit markets. Appendix A.3 presents a simple computation indicating that the main results would not change significantly, even if all countries were initially unconstrained under BT.
} 
power. ${ }^{18}$ This is an important feature of the quantitative predictions of Table 3 . Since the model under BT provides a quantitative measure of the importance of technological differences, relative to other factors, in accounting for actual dispersion, it is natural to use this information in making predictions about the likely effect of the trade regime changes.

To compute the model's moments, the unconditional long-run distributions of RY and RKY were first approximated by simulation. Second, several panels of 110 countries over 36 periods were obtained by first drawing independently 110 initial conditions from the unconditional joint distribution of states and then by iterating forward on the model's transition function for 36 periods, starting from each different initial condition. For each sample panel, a set of moments was computed which is the exact counterpart of the data moments. The results reported are long-run averages of the model's moments, computed over 20,000 sample panels.

Consistent with the discussion in Section 3, Table 3 shows that under FT the model features a substantial degree of worldwide equalization of capital-output ratios. The departure from exact equalization is simply due to the correction to measured output described in (17). As a consequence, a reduction in trade barriers that implemented FT could achieve a significant reduction in the worldwide income inequality, 7.4 percent, as measured by the change in the standard deviation of $\log \mathrm{RY}$. This effect is accounted in large part by a reduction of nearly 15 percent in the dispersion of RKY. What is perhaps more surprising, even from a qualitative standpoint, is that income inequality is also reduced when the world economy moves from BT to NT. The effect is quantitatively less significant, the decrease being just 1.3 percent, but it is also associated with a decline in the dispersion of RKY.

The key to understanding the different implications for dispersion of BT and NT is to examine how international borrowing and lending affects the capacity to accumulate capital. In this regard, it follows that under NT different countries face different domestic interest rates, whereas under BT countries unconstrained in world credit markets face the same fixed world interest rate. Formally, from the first-order conditions under both NT and BT one obtains

$$
\mathrm{E}_{\mathbf{s}}\left[\frac{\alpha y^{\prime} / k^{\prime}+\theta^{\prime}(1-\delta)}{\gamma_{\theta} \theta}\right]=\left(1+r^{d}\right)(1+\pi(\omega, \mathbf{s}))
$$

where

$$
\pi(\omega, \mathbf{s}) \equiv-\operatorname{cov}_{\mathbf{s}}\left\{\beta \gamma^{-\sigma} \frac{u^{\prime}\left(c^{\prime}\right)}{u^{\prime}(c)}, \frac{\alpha y^{\prime} / k^{\prime}+\theta^{\prime}(1-\delta)}{\gamma_{\theta} \theta}\right\}
$$

is the risk premium. Equation (18) reveals a link between the domestic interest rate, $r^{d}$, and

\footnotetext{
${ }^{18} \mathrm{I}$ decompose a variable $y$ as the part determined by technology $(x)$ and the part determined by other factors outside the model $(z)$, so that $y=x+z$. Assuming $z$ to be invariant to trade regime changes and cov $\left(x^{\prime}, z^{\prime}\right)=$ $\operatorname{cov}(x, z)$ we have $\operatorname{std}\left(y^{\prime}\right) / \operatorname{std}(y)=\sqrt{1+\alpha \Delta}-1$, where primes denote variables after the regime change, with $\Delta \equiv\left[\operatorname{var}\left(x^{\prime}\right)-\operatorname{var}(x)\right] / \operatorname{var}(x)$ and $\alpha \equiv \operatorname{var}(x) / \operatorname{var}(y)$. The model's predicted change is thus downweighted by the model's explanatory power under BT.
} 
Table 3: Cross-Sectional Dispersion in Incomes and

Capital-Output Ratios: Steady-State

\begin{tabular}{llcc}
\hline Variable & & Dispersion & $\% \Delta$ Dispersion \\
\hline RY & Data & 1.063 & - \\
& BT & 0.978 & - \\
& FT & 0.892 & $-7.39 \%$ \\
NT & 0.963 & $-1.30 \%$ \\
\hline RKY & Data & 0.632 & - \\
BT & 0.354 & - \\
FT & 0.113 & $-15.25 \%$ \\
NT & 0.306 & $-4.05 \%$ \\
\hline Notes: RY and RKY are, respectively, GDP per worker and \\
capital-output ratios relative to their world means. Disper- \\
sion is the time average of log standard deviations. \% $\Delta$ \\
Dispersion is the percentage change in actual average dis- \\
persion implied by FT and NT.
\end{tabular}

capital-output ratios. The domestic interest rate under NT is

$$
r^{d}=\left\{\mathrm{E}_{\mathbf{s}}\left[\frac{\beta \gamma^{-\sigma} u^{\prime}\left(c^{\prime}\right)}{u^{\prime}(c)}\right]\right\}^{-1}-1
$$

and it varies across countries. Under BT, instead, all unconstrained economies face the same world interest rate $r^{d}=r$.

To interpret equation (18), it is useful to recognize that, quantitatively, country differences in RKY under BT turn out to be almost entirely due to country differences in $\theta$ (see Castro (2004)). We may thus ignore country differences in $z$ when trying to understand the dispersion in RKY in the model. To develop some intuition, assume also that $\pi(\omega, \mathbf{s})$ is a constant (as it turns out, it varies little across countries). In this case, equation (18) says that capital-output ratios will be more responsive to differences in $\theta$ under BT (where there is a sizable number of economies unconstrained in world credit markets) rather than under NT, as long as $r^{d}$ under NT varies negatively with $\theta$. It turns out that $r^{d}$ does vary inversely with $\theta$. The reason is that, for a closed economy, changes in investment must be matched by changes in saving, and the domestic interest rate must adjust to give agents the right incentives. For instance, a decrease in $\theta$ makes investment cheaper, and $r^{d}$ must increase in order to entice agents to increase saving. The resulting increase in the capitaloutput ratio is thus not as large under NT. In other words, there is a leverage effect on investment when economies are open. The observed cross-sectional dispersion in $\theta$ thus translates into a higher cross-sectional dispersion in RKY under BT, rather than under NT.

An important advantage of studying the effect of trade regime changes in the context of a fullyspecified model is that we may rely upon a well-defined notion of openness, which is independent from the effect of endogenous variables. Purely empirical approaches studying the effect of openness on economic development and growth often provide results that are hard to interpret, precisely because in those cases it is very difficult to meet the exogeneity requirement. 


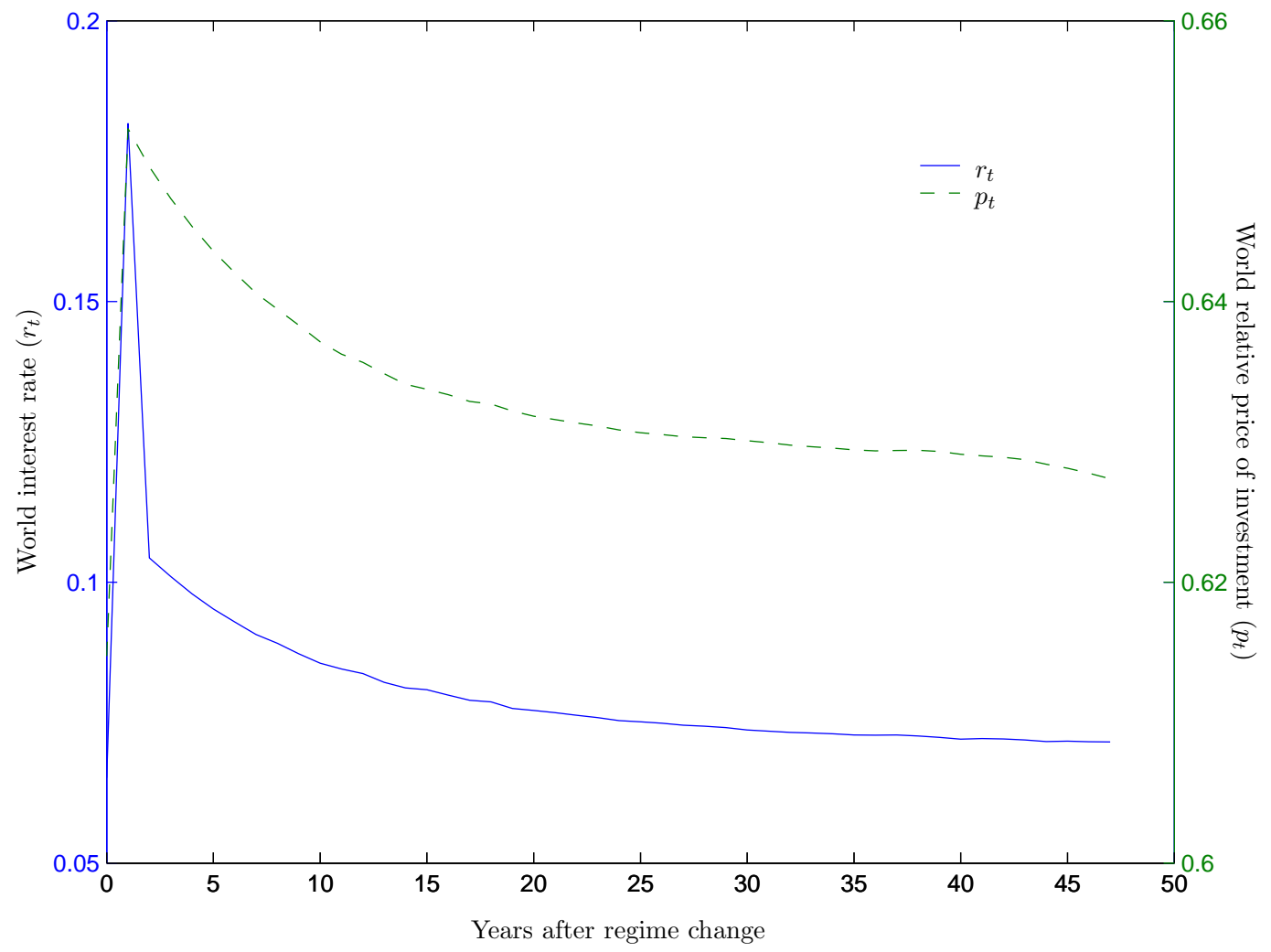

Figure 3: World Prices during Transition $(\mathrm{BT} \rightarrow \mathrm{FT})$

In this paper, there is a natural and precise definition of openness. Increased openness may be defined as a regime change which allows for at least as many trades as before. Defined in this way, Table 3 suggests that openness may actually generate an increase in worldwide income inequality, if restricted to simple borrowing and lending. Nevertheless, openness may ultimately lead to a substantial reduction in inequality across countries, by allowing for free trade between consumption and capital goods as well. While the effect of openness on world inequality is ambiguous in general, it may significantly reduce world income inequality. This depends on the specific modification of the trade arrangement. For changes in openness less stylized than the ones considered here, potentially featuring both types of modification simultaneously, the effect of openness on inequality boils down to a quantitative issue. ${ }^{19}$

It is also interesting to look at the transitional effects on inequality associated with a full liberalization of trade (move from BT to FT). The world economy is initially in the BT steadystate and, following the surprise permanent change in the trade arrangement, it will move towards

\footnotetext{
${ }^{19}$ The empirical economic development literature has emphasized an increase in the dispersion in world incomes since the 1960's - see, among many others, Parente and Prescott (1993). It is interesting to note that, under the view that the increase in openness most countries have been experiencing in the last few decades was mostly due to enhanced financial market integration, the model would be consistent with this prediction.
} 
the FT steady-state, to which it will converge only asymptotically. Appendix A.2 provides some details on the computation of the transition. The adjustment is induced by the price sequences plotted in Figure 3. One may then study the evolution over time of inequality in incomes and capital-output ratios following this regime change.

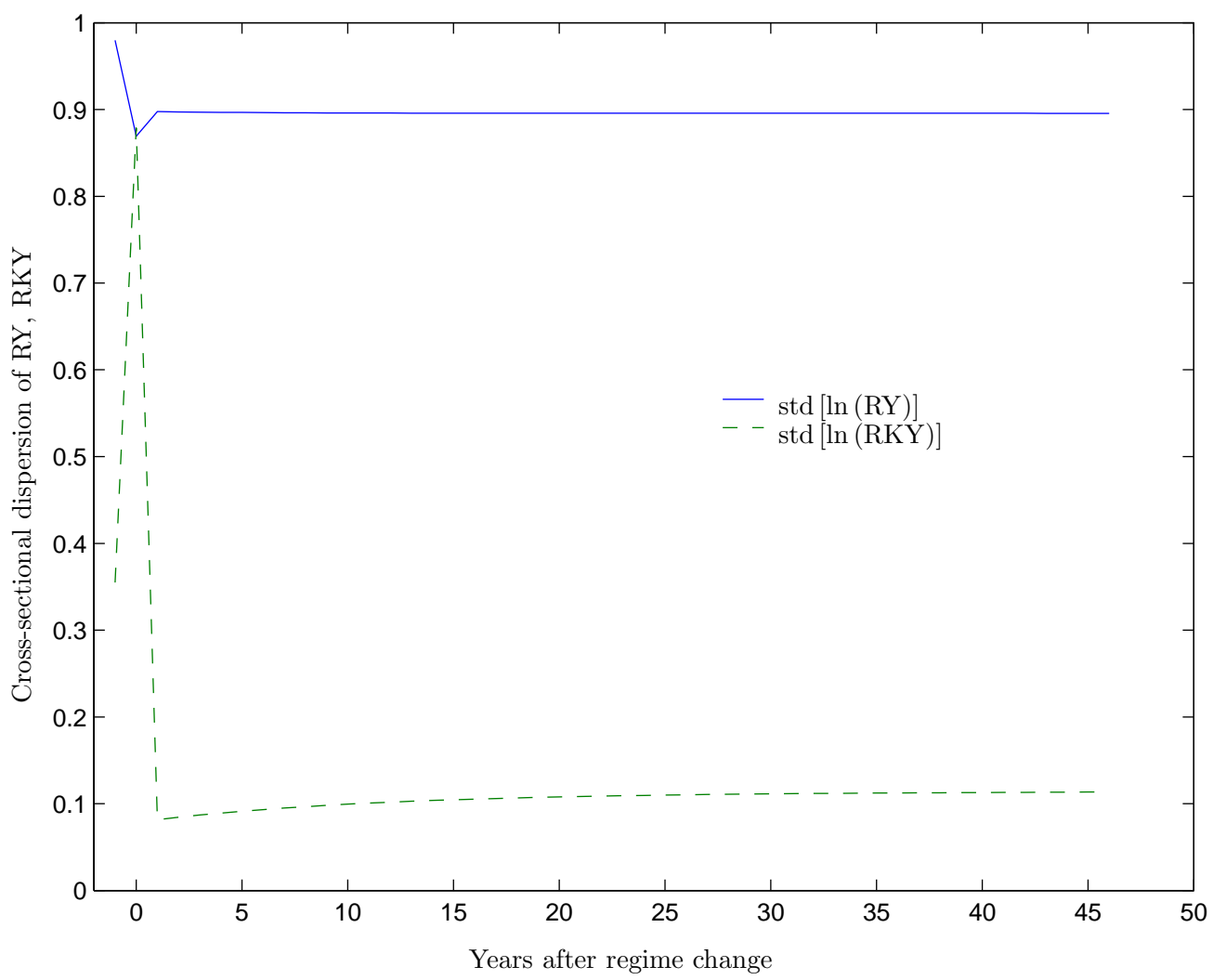

Figure 4: Transitional Dynamics of Inequality $(\mathrm{BT} \rightarrow \mathrm{FT})$

A quick glance at Figure 4 reveals that the most significant effects on inequality arise contemporaneously with the regime change. One year after abolishing all impediments to trade, the cross-country dispersion in both RY and RKY is reduced nearly to the new long-run values. The initial decrease in income inequality is accompanied by a significant increase in the variation in capital-output ratios. These large effects on impact stem from the interaction between the equalizing forces of trade in investment, and from the fact that initial capital is predetermined. There does not appear to exist a simple intuition for why this is the case, in part because output refers to measured output as defined in (17). On the one hand, the dispersion in measured output decreases, because the dominant effect is a decrease in the cross-country variation of investment. On the other hand, the dispersion in capital-output ratios increases, since the dominant effect is a decrease in the covariance between measured output and capital. This decrease is due to the fact that countries with low initial capital now invest a large amount of resources, which translates into a large amount 
of capital goods, and thus large measured income, with a fixed world price of investment.

\subsection{Efficiency}

To assess the implications for efficiency of the different trade regimes, one may look at the changes in world output and, more importantly, at the changes in welfare. For the welfare effects I focus on the consumption equivalent. In particular, I compute the percent increase in consumption common across countries, dates and states of nature, such that agents would be on average indifferent between remaining under BT and changing the trade regime by moving to either FT or NT.

For both experiments, I first perform a steady-state comparison. ${ }^{20}$ Formally, I compute the equivalent variation in steady-state consumption $\lambda$ given by

$$
\int_{S} \mathrm{E}_{0} \sum_{t=0}^{\infty}\left(\beta \gamma^{1-\sigma}\right)^{t} u\left[(1+\lambda) c_{t}^{\mathrm{BT}}\left(\omega_{0}, \mathbf{s}_{0}\right), 1\right] d \psi^{\mathrm{BT}}=\int_{S} v^{j}\left(\omega_{0}, \mathbf{s}_{0}\right) d \psi^{j}
$$

for $j=\mathrm{FT}, \mathrm{NT}$ and where $\left\{c_{t}^{\mathrm{BT}}\left(\omega_{0}, \mathbf{s}_{0}\right)\right\}$ is an equilibrium consumption sequence under $\mathrm{BT}$ for country $\left(\omega_{0}, \mathbf{s}_{0}\right) .{ }^{21}$ Table 4 reports the outcome of the steady-state analysis.

Table 4: Efficiency in the Long-Run

\begin{tabular}{l|cccccc}
\hline Experiment & $\lambda$ & $\Delta \% c$ & $\Delta \% k^{d}$ & $\Delta \% y$ & $\Delta \% y^{m}$ & $\Delta \% \operatorname{std}(\ln c)$ \\
\hline $\mathrm{BT} \rightarrow \mathrm{NT}$ & $-2.01 \%$ & $-1.51 \%$ & $-8.05 \%$ & $-2.09 \%$ & $-3.49 \%$ & $0.34 \%$ \\
$\mathrm{BT} \rightarrow \mathrm{FT}$ & $35.01 \%$ & $29.85 \%$ & $64.25 \%$ & $31.99 \%$ & $40.32 \%$ & $-4.01 \%$ \\
\hline Notes: The first column reports the welfare change. The second to fifth columns report \\
the percent change in average consumption, domestic capital, GDP in consumption \\
units and measured GDP, respectively. The last column reports the percent change in \\
consumption variability.
\end{tabular}

There are two important observations. First, there is an extremely large welfare gain associated with a full liberalization of trade. This of course begs several questions, which the paper will try to address next: Where are the large gains coming from? Will they vanish once the transition is accounted for? Second, fully restricting trade entails only a relatively modest welfare loss, much less significant than the gain from trade liberalization. The comparison between the two magnitudes is important: it suggests that trade in goods is likely to be much more important than access to financial markets in raising living standards.

Table 4 attempts to give a rough idea of the composition of these welfare changes. First, associated with any of the two regime changes, there are variations in welfare both due to changes in the level of consumption, and also due to changes in consumption variability. The dominant effect is clearly the level effect. In fact, not only the increase in consumption variability itself is

\footnotetext{
${ }^{20}$ The steady-state comparison is meant only as a preliminary calculation. Naturally, since not just the trade regime but also the cross-sectional distribution are changing in each experiment, the results are hard to interpret. This will not be the case in Table 5, when transitional effects are accounted for.

${ }^{21}$ Computing $\lambda$ in practice involved evaluating lifetime utility for a large number of countries, which are independent draws from the appropriate long-run distributions, through cubic spline interpolation.
} 
quantitatively small, also the associated welfare change is likely to be rather small. Most of the work in this class of models has consistently found tiny welfare effects arising from complete consumption smoothing - e.g. see Lucas (1987), and much of the subsequent literature on the welfare costs of business cycles. Hence, any insurance gains or losses associated with openness should contribute little to the welfare numbers.

The long-run changes in consumption levels are naturally accounted for by long-run changes in income levels. Table 4 reports the magnitude of these changes. This answers the question of how openness impacts on incomes. Significant work in the cross-country growth regression literature, reviewed recently in Rodríguez and Rodrik (2000), has tried to answer the same question. Frankel and Romer (1999), in particular, estimate (although not very precisely) that an increase in one percentage point in the component of the trade share that is induced by geographical factors (their measure of openness) causes a large increase in output per capita of about 2-3 percent. The current framework also predicts a large increase in long-run incomes as a result of higher openness, much more significant in terms of reducing barriers to trade in capital goods. The magnitudes, however, appear to be substantially higher in Table $4 .^{22}$ Notice that, in fact, there are no long-run growth effects in the current setup, as as all growth in the model ultimately originates from the world technology frontier. Still, there will be important transitional effects, as can be seen from Figure 4.

I will now concentrate on the trade liberalization regime change. One important question concerns the transition to the new steady state. That is, one would like to know whether the large welfare gain comes mostly from capital accumulation. Since the change in the capital stock results in part from capital being produced more efficiently worldwide, but also in part from intertemporal consumption decisions, the full effect on welfare is necessarily missed by simple steady-state comparisons.

To answer this question, one has to explicitly compute the transition from BT to FT. To incorporate the transitional effects in the welfare numbers, the right-hand-side of (19) must be replaced by $\int_{S} v_{0}(\omega, \mathbf{s}) d \psi_{0}$, where $v_{0}$ and $\psi_{0}$ are the value function and the cross-sectional distribution that obtain at time $t=0$, the period the regime change takes place. Importantly, $\psi^{\mathrm{BT}}$ differs from $\psi_{0}$ only due to instantaneous price movements, occurring in the period of the regime change. This means the relevant initial conditions $\left(k_{0}, b_{0}\right.$ and $\left.\mathbf{s}_{0}\right)$ are held constant in this experiment (see the Appendix A.2 for further details).

With the transitional effects factored in, the welfare gain only drops to 24.74 percent, which is still a very large number. The dynamics of world output $\left(\bar{Y}=\int y^{m} d \psi\right)$ and world capital

\footnotetext{
${ }^{22}$ As mentioned before, changes in openness in the current analysis are defined as trade regime changes, which do not have a counterpart in the simple one-dimensional measures of openness considered in the empirical growth literature. For this reason, one may not directly compare the numbers from Frankel and Romer (1999) with those in Table 4. In addition to providing an estimate of the effect of openness on incomes, one advantage of the current approach is in allowing for a welfare analysis. According to Table 4, incomes systematically overstate the more relevant welfare changes.
} 
$\left(\bar{K}=\int k^{d} d \psi\right)$ following the regime change from BT to FT is depicted in Figure 5.

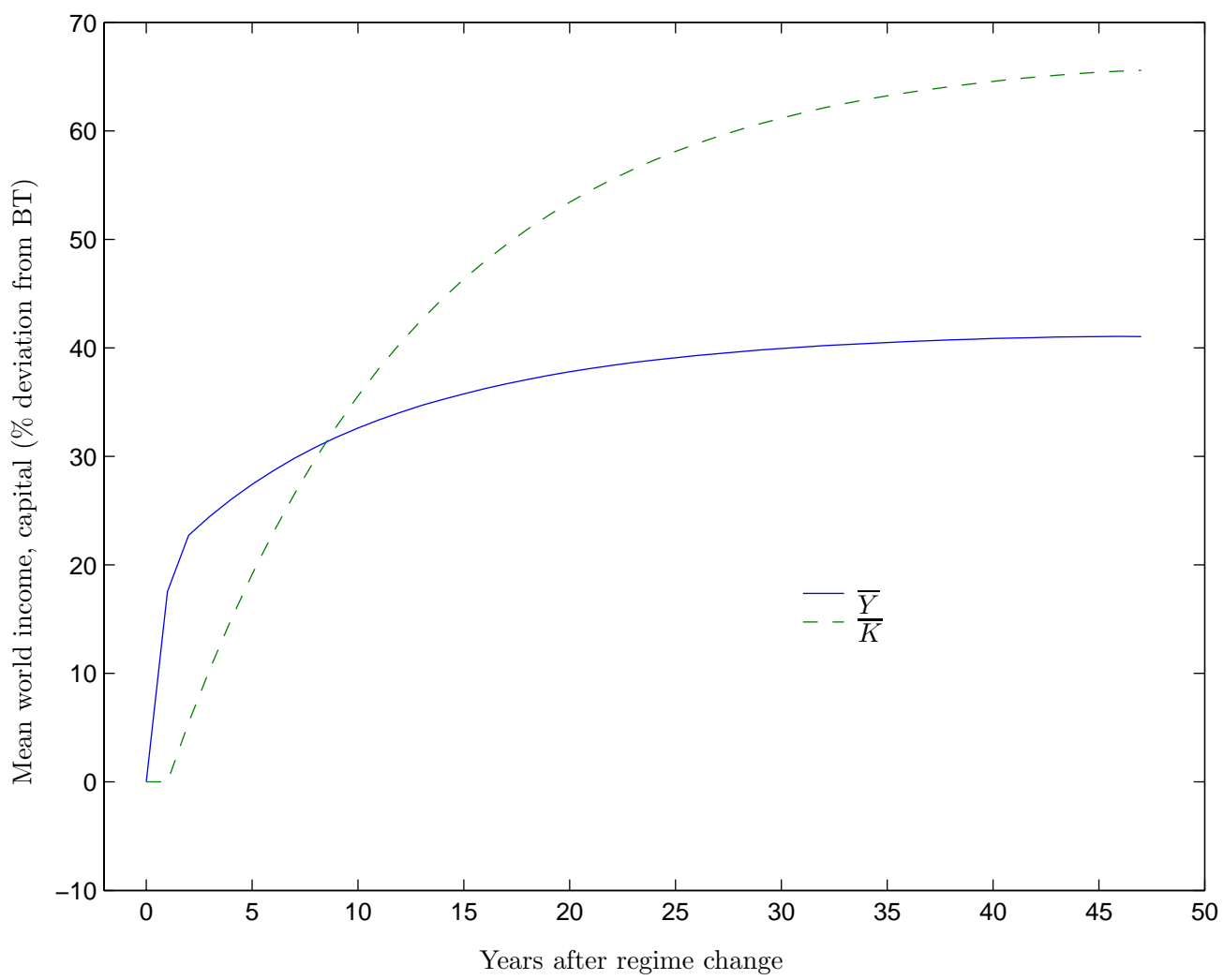

Figure 5: Transitional Dynamics of Efficiency $(\mathrm{BT} \rightarrow \mathrm{FT})$

The first thing to notice is the large increase in output that occurs on impact, without an associated increase in capital. As much as half of the efficiency gain is enjoyed contemporaneously with the regime change. This purely static efficiency gain results from trade specialization. Under BT, countries that are inefficient at producing investment goods are forced to do so, since this is the only way they may obtain capital. Under FT, these countries may simply concentrate in the production of consumption goods, where they have a comparative advantage, and simply import capital goods from abroad. The worldwide allocation of capital and labor across sectors is improved, and this is what drives the initial large gain. Importantly, this efficiency gain does not involve any sacrifice in terms of consumption, and it helps explain why the welfare gain remains high when transitional effects are factored in.

Figure 5 reveals that there are important dynamics as well. The full benefits of opening up fully to trade arise only through time, via capital accumulation, requiring a time horizon of about 50 years after abolishing trade barriers to be enjoyed in their entirety. The reason why countries choose to accumulate more capital should be clear. Due to specialization in production, the marginal productivity of capital is now higher in each single country, since it is governed by the sectoral 
productivity level which is relatively higher. Each country experiences something analogous to a increase in TFP in the standard neoclassical growth model and, as in the standard model, this fosters capital accumulation.

An additional benefit from computing the transition is that one may look at the breakdown of the welfare gains by subgroups of countries. In order to capture the key heterogeneity in the welfare gains, Table 5 concentrates on selected quantiles of the model's joint cross-sectional distribution of RY and RKY under BT. As before, the computation of consumption equivalents is based upon the initial distribution $\psi_{0}$. However, for each cell in the table, integration is now done only over individual states giving rise to values of RY and RKY in the appropriate ranges.

Table 5 concentrates on countries in the tails of the joint distribution of incomes and capitaloutput ratios (top and bottom 10 percent) and on "typical" countries, those roughly in the center of this distribution. In order to interpret the results in this table, notice that cross-country differences in RKY capture mostly the differences in $\theta$, whereas differences in RY capture mostly the differences in $z .^{23}$

Table 5: Distributional Welfare Effects $(\mathrm{BT} \rightarrow \mathrm{FT})$

\begin{tabular}{c|ccc}
\hline RKY RY & $<0.1$ & $1 / 3-2 / 3$ & $>0.9$ \\
\hline$<0.1$ & 0.509 & 0.459 & 0.461 \\
$1 / 3-2 / 3$ & 0.195 & 0.181 & 0.189 \\
$>0.9$ & 0.217 & 0.214 & 0.257 \\
\hline
\end{tabular}

Notes: Table entries are average consumption equivalents for countries in specific interpercentile ranges of the joint long-run cross-sectional distribution of RY and RKY under BT.

The largest gains are to be enjoyed by very poor countries with low capital-output ratios, some of which may have equivalent consumption increases twice as large as the world average (25 percent). Countries that enjoy the least gains are those situated roughly in the center of the distribution, whereas countries enjoying the higher gains are those most different from the world norm. Most of the heterogeneity in the welfare gains occurs along the RKY dimension, suggesting the importance of the relative efficiency in capital goods production. Countries with significantly inefficient investment goods sectors, thus with lower capital-output ratios, are the ones who stand to gain the most.

Table 6 identifies which countries fall into each cell of Table 5. To do so, it uses the information from the PWT on the actual joint distribution of RY and RKY in 1996. This is the model's estimate of the welfare gain actual countries would stand to enjoy, had the full trade liberalization taken place. One interesting observation is that many of the countries that happen to be in the

\footnotetext{
${ }^{23}$ Under BT, it turns out that cross-country differences in $\theta$ account for about all the dispersion in RKY but only for about 15 percent of the dispersion in RY - see Castro (2004).
} 
center are located in Latin America. ${ }^{24}$ Some of these countries pursued import-substitution policies throughout the time span of the PWT which advocated, in particular, the domestic production of equipment goods that would normally be imported at lower prices. The findings in Table 5 are suggestive in this regard, and may perhaps offer some insight in help explaining their adoption of these policies.

Table 6: Joint Distribution of RY and RKY in the PWT in 1996

\begin{tabular}{c|c|c|c}
\hline RKY RY & $<0.1$ & $1 / 3-2 / 3$ & $>0.9$ \\
\hline$<0.1$ & $\begin{array}{c}\text { ETH,MOZ } \\
\text { RWA,UGA }\end{array}$ & EGY & - \\
\hline $1 / 3-2 / 3$ & GNB & $\begin{array}{c}\text { BWA,COL,CPV,CRI,DOM } \\
\text { FJI,GAB,HND,IDN,IRN } \\
\text { JOR,MAR,NAM,PAN,PHL } \\
\text { PNG,TUN,TUR,URY,ZWE }\end{array}$ & IRL \\
\hline$>0.9$ & TZA & ROM & AUT,BEL \\
FRA,NOR
\end{tabular}

Notes: Country codes are from the Data Appendix of PWT6.1, described in Heston, Summers, and Aten (2002). The corresponding countries are listed in Appendix A.1.

\subsection{Discussion}

This paper has tried to quantify the inequality and efficiency effects on economic development of different worldwide trade regimes. It may be worth pointing out the similarity in spirit between this exercise and the one in Lucas (1987). In his well-known book, Lucas asked what would the welfare effects be if the economy was able to completely eliminate the cyclical fluctuations in aggregate consumption. Analogously, the idea here has been to consider simple changes in the worldwide trade arrangement, which are clearly specified in the context of the model. Similarly to Lucas (1987), the changes in the trade regime are admittedly extreme, and the analysis is silent about the precise mechanism through which changes in policy variables may affect trade barriers. The idea is quite simply to provide an upper bound for the potential effects of the trade regime changes, namely in terms of welfare.

An important difference, however, arises in terms of the results, particularly regarding trade liberalization. Since Lucas (1987) finds tiny welfare gains, the issue of relaxing the extreme nature of the experiment, and that of being more explicit about the policy mechanism, becomes a relatively unimportant discussion. In the current paper, instead, the "first pass" on the trade liberalization question produces extremely large welfare gains. Unlike in Lucas (1987), here it does become important to discuss the extent to which the large upper bound is a robust result. A careful

\footnotetext{
${ }^{24}$ Brazil, Chile, Ecuador, Paraguay and Venezuela are all very close to the middle cell. The US has one of the highest RY in 1996, but not one of the highest RKY.
} 
discussion must be necessarily left for future research, but I will consider some possible concerns next.

One first issue is whether the world economy would be able to get sufficiently close to the FT arrangement through any feasible policy change. In fact, under FT, both physical capital and consumption would have to be extremely flexible internationally, whereas some of the barriers to trade, such as geographical factors, could hardly be eliminated. ${ }^{25}$ In other words, the trade liberalization experiment assumes all goods become tradable, whereas in reality this would not happen. Dealing with this problem does not appear to be an easy task. In the context of the current setting, a partial answer may be to identify cross-country differences in the relative productivity of investment goods through differences in investment prices relative to tradable consumption prices. Presumably, this would lead to a lower cross-country dispersion of investment-specific productivities, and hence lower gains from trade. Hsieh and Klenow (2003), however, document that the price of tradable consumption is still significantly positively correlated with incomes, although less than the price of nontradable consumption. Compared with the price of all consumption (the one used in Section 5 in computing relative investment prices), the price of tradable consumption displays a reasonably similar association with incomes. This evidence suggests that, based upon the price of investment relative to tradable consumption, there would be lower cross-country variation in investment-specific productivities, but presumably not enough to dramatically lower the welfare gains.

An alternative way to dealing with this problem is to introduce transportation costs in the model. One option, following much of the international trade literature, is to specify them as "iceberg costs", such that a fraction of every unit of consumption that is traded is simply lost in the process. This generates a no-intratemporal-trade region at every point in time, where a group of countries with levels of $\theta$ sufficiently close to the world relative investment price do not find it profitable to engage in intratemporal trade. These countries interact with the rest of the world as if they were in the BT trade regime. The remaining countries interact as in the FT trade regime, and they specialize completely either in the production of consumption goods, or in the production of investment goods. An important obstacle to this approach is that it is very hard to obtain reliable information on the quantitative magnitude of transportation costs, something which would be needed for calibration. Appendix A.3 develops a simple back-of-the-envelope calculation, based upon the full model, to try to get some idea of the magnitude of transportation costs that would reduce significantly the gains from liberalizing trade in goods. The result from this calculation suggests that transportation costs would have to be in excess of about $1 / 3$ of the sale price at the

\footnotetext{
${ }^{25}$ Eaton and Kortum (2001) estimate the amount of barriers to trade implied by actual trade flows in equipment, some of which would be of strictly geographical nature and therefore hardly removable. In addition, also the structures component of investment is likely to remain relatively less tradable. The current framework could in principle be extended to account explicitly for differences between equipment and structures along the lines of Greenwood, Hercowitz, and Krusell (1997).
} 
production origin, and probably much larger, in order to have significant effects.

Another potential issue is whether observed differences in relative investment prices are mostly due to the presence of tariffs, taxes, or similar types of investment distortions. ${ }^{26}$ If this were the case, then one would not be able to argue about these differences being mostly technology-induced, and thus exploitable through specialization and trade. Hence, it would be important to know whether higher relative investment prices in poor countries are simply due to higher barriers to capital accumulation. Distortions certainly account for some of the observed world dispersion in investment prices. The evidence by Eaton and Kortum (2001), however, reveals that even though the cross-country variability in equipment prices per se is large, it is not systematically associated with incomes. In fact, if anything, richer countries have slightly higher equipment prices. ${ }^{27}$ In turn, relative equipment prices and incomes are strongly negatively correlated. This suggests that tariffs are unlikely to account for most of the cross-country variation in relative investment prices that is systematically associated with incomes. The technological interpretation pursued in this paper looks like a more plausible candidate.

Still regarding relative investment prices, there is also an argument pointing to the welfare numbers being underestimated. The reason is that measured international differences in the relative price of investment goods most likely underestimate differences in the true effective price. This effective price of capital corresponds to a broad notion that includes all investment costs (like the cost of learning how to operate the capital equipment) and not just those measured by market prices. This notion would clearly be the most appropriate to identify investment-specific technological indexes. Eaton and Kortum (2001) attempt to infer effective price differences from trade flows in equipment alone and conclude that effective prices are indeed much more dispersed internationally than observed market prices.

Yet a further issue is that productivity is unlikely to be invariant to changes in the trade regime, contrary to what is assumed throughout the paper. There is in fact plant-level empirical evidence pointing to significant productivity gains associated with trade liberalization - see for example Pavcnik (2002). This effect is presumably going to be stronger in the most inefficient economies, those farther away from the technology frontier. In this case, one might expect trade liberalization to contribute directly to an increase the average level of productivity in the world economy, while at the same time to reduce cross-country technology differences. While a full investigation of this issue is outside the scope of this paper, one is tempted to conjecture that, once trade liberalization

\footnotetext{
${ }^{26}$ This is the view of the relative price data taken by Chari, Kehoe, and McGrattan (1997). Note that investment and consumption prices in the Penn World Tables are final sale prices and therefore incorporate the effect of tariffs, taxes and explicit transportation costs.

${ }^{27}$ Aggregate investment prices themselves also have a slightly positive correlation with incomes (equal to 0.28 in 1996, according to the Penn World Table data). Hsieh and Klenow (2003) make the same point. Using theory as a tool for measurement, they argue that the evidence clearly favors the view of a technology-induced variation in relative prices, rather than an investment distortions-induced one.
} 
is allowed to impact on productivity, the gains from trade can only be larger. Does this mean the gains from liberalizing trade in goods are also potentially larger than the gains from liberalizing financial markets? Not necessarily, as one may also argue that the lack of access to credit is what is key in preventing poor countries from gaining access to the technologies of rich countries. In this case, there could be little technological differences left to be exploited by trade in goods, and most of the gains from trade would be associated with liberalizing financial markets.

To summarize this discussion, there does not appear to be an obvious reason that would make such extremely large welfare gains associated with a liberalization of trade simply vanish. On balance, there are reasons suggesting the welfare numbers could be refined downwards. This refinement is an important task that needs to be addressed in future work. At the same time, there clearly is sufficient room for the numbers to decline, and it seems likely that the main message of the paper, a large welfare gain associated with a liberalization of trade, would persist.

I now discuss the robustness of the result that fully liberalizing intratemporal trade in goods, rather further integration of financial markets, is the regime change that generates the largest welfare gains. There are at least two issues that could be raised. First, one could ask whether increasing the sophistication of international financial markets, by allowing for trade in contingent claims, would change this conclusion. I would argue that this is unlikely to be the case. In fact, the literature focusing on related setups has generally found very small welfare gains from perfect international risk-sharing, two early examples being Cole and Obstfeld (1991) and Backus, Kehoe, and Kydland (1992). Second, one could also ask whether liberalizing further credit markets, in the sense of driving the fraction of constrained countries further down relative to BT, could significantly alter the results. As pointed out previously, Appendix A.3 computes what may be regarded as an upper bound for the gain from a complete liberalization of credit markets, and finds it to be still significantly smaller than the gain from liberalizing trade in goods. The bottom line is that liberalizing financial markets does not allow countries to exploit their different sector-specific productivities, and this is what is key in generating the large welfare gains.

\section{Conclusion}

This paper studies the consequences for economic development of alternative international trade arrangements. Starting from a benchmark borrowing and lending arrangement subject to an upper bound on foreign debt, it analyzes the effects of moving into each of two alternative arrangements, by fully restricting trade and by fully liberalizing trade.

Different changes in trade arrangements have different consequences on cross-country income inequality and welfare. In this respect, there are two main findings. First, the effect of openness on worldwide income inequality depends in a nontrivial way on the specific changes in the trade arrangement. The cross-sectional dispersion in world incomes would decrease only by about 1.4 
percent if a policy were implemented that entirely eliminated international financial flows, and thus all international trade, but it would decrease by a much higher 7.8 percent if openness were further enhanced by allowing countries to trade capital freely for consumption goods.

Second, in terms of the welfare implications, financial markets alone turns out to be a poor substitute for a full liberalization of international movements in goods. The long-run average welfare cost of going into autarky is only about 2 percent in terms of the consumption equivalent, but the welfare gain of allowing for unrestricted trade in goods is instead a very large 35 percent average increase in steady-state consumption. A significant part of these large welfare gains, as much as half, arise from specialization in production and from improvements in the international allocation of physical capital. For this reason, when transition effects are taken into account, the average welfare gain remains at a very high 25 percent increase in consumption. These benefits are particularly high for countries with low capital-output ratios, especially among the very poorest, some of which may enjoy equivalent consumption increases twice as high as the world average.

Put in other words, with the degree of international productivity differences specific to the production of investment goods we are able to infer from price data, it may be of little use if a developing country is able to obtain abroad all the funds it needs to invest domestically, in case a substantial part of the capital goods have to be home-produced anyway. Very large benefits would instead arise if capital goods could be produced in the most efficient location and then imported. In this case, developing countries would be able to specialize in producing and exporting consumption goods, where they have a comparative advantage.

This finding calls perhaps for an important shift in policy emphasis: efforts should be concentrated more on the reduction of all sorts of barriers preventing trade in capital goods, including barriers to trade in consumption goods, and less in promoting worldwide access to international credit markets.

\section{A Appendix}

\section{A.1 Data Set}

I concentrate on a panel of 110 countries from 1961 to 1996, a subset of the Penn World Table (PWT6.1) data set, described in Heston, Summers, and Aten (2002). This is the largest panel with complete data for real GDP per worker and real gross investment in 1996 international prices. Real gross investment is computed as the product of the PWT6.1 series KI, POP, and RGDPCH. Capital stocks are constructed by the perpetual inventory method, with countries assumed to be in steady-state in 1961. The reader is referred to Castro (2004) for the full details. The complete list of the countries included in the data set is the following (in parenthesis are the country codes reported in Table 5): Algeria, Australia, Austria (AUT), Burundi, Belgium (BEL), Benin, 
Burkina Faso, Bangladesh, Bolivia, Brazil, Barbados, Botswana (BWA), Central African Republic, Canada, Switzerland, Chile, China, Côte d'Ivoire, Cameroon, Republic of Congo, Colombia (COL), Comoros, Cape Verde (CPV), Costa Rica (CRI), Cyprus, Denmark, Dominican Republic (DOM), Ecuador, Egypt (EGY), Spain, Ethiopia (ETH), Finland, Fiji (FJI), France (FRA), Gabon (GAB), U.K., Ghana, Guinea, Gambia, Guinea-Bissau (GNB), Greece, Guatemala, HongKong, Honduras (HND), Indonesia (IDN), India, Ireland (IRL), Iran (IRN), Iceland, Israel, Italy, Jamaica, Jordan (JOR), Japan, Kenya, Republic of Korea, Sri Lanka, Lesotho, Luxembourg, Morocco (MAR), Madagascar, Mexico, Mali, Mozambique (MOZ), Mauritania, Mauritius, Malawi, Malaysia, Namibia (NAM), Niger, Nigeria, Nicaragua, Netherlands, Norway (NOR), Nepal, New Zealand, Pakistan, Panama (PAN), Peru, Philippines (PHL), Papua New Guinea (PNG), Portugal, Paraguay, Romania (ROM), Rwanda (RWA), Senegal, Singapore, Sierra Leone, El Salvador, Sweden, Seychelles, Syria, Chad, Togo, Thailand, Trinidad and Tobago, Tunisia (TUN), Turkey (TUR), Taiwan, Tanzania (TZA), Uganda (UGA), Uruguay (URY), USA, Venezuela, South Africa, Zaire, Zambia, Zimbabwe (ZWE).

\section{A.2 Numerical Algorithm to Compute Transition}

This appendix describes in some detail the numerical algorithm used to compute the world economy's transition from the BT steady-state to the FT steady-state. The algorithm was programmed in Fortran 90 and is available from the author upon request. At $t=0$, the period when the surprise regime change occurs, I assume that economies have access to the market for new capital goods, but are not able to rent capital services. The alternative assumption that economies have access to both types of trade on impact, if anything, should decrease the importance of transitional effects. The numerical algorithm may be described in the following eight steps.

1. Guess on $n$, the approximate number of periods it takes to complete he transition.

2. Guess on a sequence of prices $\left\{p_{t}\right\}_{t=0}^{n}$ and set $p_{n+1}=p_{n}$.

3. Set $r_{0}=r^{\mathrm{BT}}$ and solve for $\left\{r_{t+1}\right\}_{t=0}^{n}$ by ensuring that the markets for new capital and foreign bonds clear at $t=0$ and that all three markets clear from $t=1$ onward. That is, iterate forward in recursive fashion on

$$
r_{t+1}=\frac{1}{\gamma_{\theta} p_{t}}\left\{\frac{A_{t}+(1-\delta) B_{t}}{\gamma \int\left[\alpha z_{t+1} \max \left\{1, p_{t+1} / \theta_{t+1}\right\}\right]^{\frac{1}{1-\alpha}} d \psi_{t+1}}\right\}^{\alpha-1}+\frac{p_{t+1}}{\gamma_{\theta} p_{t}}(1-\delta)-1
$$


for $t=0, \ldots, n$, where

$$
\begin{aligned}
A_{0} & \equiv \int\left(z_{0} / \theta_{0}\right) k_{0}^{\alpha} I_{\left\{p_{0} \geq \theta_{0}\right\}} d \mu_{0} \\
A_{t} & \equiv\left[\frac{\gamma_{\theta} p_{t-1}\left(1+r_{t}\right)-p_{t}(1-\delta)}{\alpha p_{t}}\right]^{\frac{\alpha}{\alpha-1}} \int\left(z_{t} / \theta_{t}\right) I_{\left\{p_{t} \geq \theta_{t}\right\}} d \psi_{t}, \text { for } t=1, \ldots, n \\
B_{0} & \equiv \int k_{0} d \mu_{0} \\
B_{t} & \equiv\left[\frac{\gamma_{\theta} p_{t-1}\left(1+r_{t}\right)-p_{t}(1-\delta)}{\alpha}\right]^{\frac{1}{\alpha-1}} \int\left[z_{t} \max \left\{1, p_{t} / \theta_{t}\right\}\right]^{\frac{1}{1-\alpha}} d \psi_{t}, \text { for } t=1, \ldots, n
\end{aligned}
$$

and where $\mu_{0}$ is the long-run cross-sectional distribution over $\left(k_{0}, b_{0}, \mathbf{s}_{0}\right)$, which is induced by $\psi^{\mathrm{BT}}$, by the equilibrium decision rules under BT and by the stochastic process for $\mathbf{s}$.

4. Given the whole price sequences $\left\{p_{t}\right\}_{t=0}^{n+1}$ and $\left\{r_{t}\right\}_{t=0}^{n+1}$, solve the country's problem at $t=$ $0, \ldots, n$ by backward induction, starting from $v_{n+1}=v^{\mathrm{FT}}$

$$
v_{t}\left(\omega_{t}, \mathbf{s}_{t}\right)=\max _{x_{t+1}}\left\{u\left(\omega_{t}-\gamma x_{t+1}\right)+\beta \gamma^{1-\sigma} \mathrm{E}_{t} v_{t+1}\left(\omega_{t+1}, \mathbf{s}_{t+1}\right)\right\}
$$

subject to

$$
\begin{aligned}
\omega_{t+1} & \equiv e\left(\mathbf{s}_{t+1}\right)+\left(1+r_{t+1}\right) x_{t+1} \\
e\left(\mathbf{s}_{t+1}\right) & \equiv(1-\alpha)\left[\frac{\gamma_{\theta} p_{t}\left(1+r_{t+1}\right)-p_{t+1}(1-\delta)}{\alpha}\right]^{\frac{\alpha}{\alpha-1}}\left[z_{t+1} \max \left\{1, p_{t+1} / \theta_{t+1}\right\}\right]^{\frac{1}{1-\alpha}} \\
\gamma x_{t+1} & \geq-\eta \omega_{t} .
\end{aligned}
$$

Section 4 briefly describes how to solve the country's problem given prices. As part of the solution, one obtains a sequence of decision rules $\left\{x_{t+1}\left(\omega_{t}, \mathbf{s}_{t}\right)\right\}_{t=0}^{n}$ and an initial value function $v_{0}\left(\omega_{0}, \mathbf{s}_{0}\right)$.

5. The initial distribution $\mu_{0}$ and the initial prices $\left(p_{0}, r_{0}\right)$ induce an initial distribution $\psi_{0}$ over $(\omega, \mathbf{s})$, where

$$
\omega_{0}=z_{0} \max \left\{1, p_{0} / \theta_{0}\right\} k_{0}^{\alpha}+p_{0}(1-\delta) k_{0}+\left(1+r_{0}\right) b_{0}
$$

6. With the initial condition $\psi_{0}$, one may iterate forward on the system's transition function, induced by the decision rules from step 4 and by the stochastic process for $\mathbf{s}$, to obtain a sequence of distributions $\left\{\psi_{t}\right\}_{t=0}^{n}$. This is accomplished by computing many (in practice 2 million) sample paths for $(\omega, \mathbf{s})$ of length $n+1$ each, starting from many different initial conditions which are independent draws from $\psi_{0}$.

7. At each period $t$ it is then possible to compute the excess world demand for foreign bonds as

$$
x s d_{t} \equiv \int x_{t+1}\left(\omega_{t}, \mathbf{s}_{t}\right) d \psi_{t}-\gamma_{\theta} p_{t} \int\left[\frac{\alpha z_{t+1} \max \left\{1, p_{t+1} / \theta_{t+1}\right\}}{\gamma_{\theta} p_{t}\left(1+r_{t+1}\right)-p_{t+1}(1-\delta)}\right]^{\frac{1}{1-\alpha}} d \psi_{t+1} .
$$


To compute the transition, the algorithm searches for a sequence $\left\{p_{t}\right\}_{t=0}^{n}$ such that $x s d_{t} \approx 0$ for $t=0, \ldots, n$. This requires solving a system of $n+1$ nonlinear equations which, in practice, may be accomplished by some multidimensional nonlinear equation solver, for instance Broyden's multidimensional secant algorithm (see Judd, 1998).

8. The final step requires checking whether $p_{n+1} \approx p^{\mathrm{FT}}$ and $r_{n+1} \approx r^{\mathrm{FT}}$. If this is the case, then the initial guess of an $n$-period transition is appropriate. Otherwise, $n$ has to be increased. In practice, $n=50$ provided a reasonably good approximation (for the welfare numbers in particular, increasing $n$ from 25 to 50 did not change the results significantly).

\section{A.3 Transportation Costs}

This appendix presents a simplified version of the full model in the main text, to assess the potential effect of nontrivial transportation costs for the result that liberalizing trade in goods produces very large efficiency gains. The idea of this exercise is to provide a simple back-of-the-envelope calculation.

The first step is to assess whether the simplified model version is useful. This is done by showing that it does a good job at approximating the results of Table 4. To simplify the algebra, the focus will be on model's output, $y$, instead of measured output, $y^{m}$. Output for a given country in each of the three trade regimes may be written as:

$$
\begin{aligned}
y^{\mathrm{NT}} & =z^{1 /(1-\alpha)}\left(\frac{k^{\mathrm{NT}}}{y^{\mathrm{NT}}}\right)^{\alpha /(1-\alpha)} \\
y^{\mathrm{BT}} & =z^{1 /(1-\alpha)}\left(\frac{k^{\mathrm{BT}}}{y^{\mathrm{BT}}}\right)^{\alpha /(1-\alpha)} \\
y^{\mathrm{FT}} & =\left[z \max \left\{1, \frac{p}{\theta}\right\}\right]^{1 /(1-\alpha)}\left(\frac{k^{\mathrm{FT}}}{y^{\mathrm{FT}}}\right)^{\alpha /(1-\alpha)} .
\end{aligned}
$$

To obtain simple expressions for the capital-output ratio, assume countries are in steady-state. In this case, it follows that:

$$
\begin{aligned}
\frac{k^{\mathrm{NT}}}{y^{\mathrm{NT}}} & =\frac{\alpha}{\theta\left(r^{\mathrm{NT}}+\delta\right)} \\
\frac{k^{\mathrm{BT}}}{y^{\mathrm{BT}}} & =\frac{\alpha}{\theta\left(r^{\mathrm{BT}}+\delta\right)} \\
\frac{k^{\mathrm{FT}}}{y^{\mathrm{FT}}} & =\frac{\alpha}{p\left(r^{\mathrm{FT}}+\delta\right)}
\end{aligned}
$$

where $r^{\mathrm{NT}} \equiv \gamma^{\sigma} / \beta-1=0.083$, with $\gamma_{\theta}=1$. As for $r^{\mathrm{BT}}$ and $r^{\mathrm{FT}}$, assume they take on the equilibrium values reported in the main text, respectively 0.065 and 0.073 . Assume also that each country has a different pair $(z, \theta)$, with these pairs distributed according to the stochastic process considered in the main text. 
In this case, it is relatively easy to compute worldwide output $\bar{y}^{j} \equiv \int y^{j} d \psi$, for $j=\mathrm{NT}, \mathrm{BT}, \mathrm{FT}$. With this information, it follows that $\bar{y}^{\mathrm{NT}} / \bar{y}^{\mathrm{BT}}=0.93$, and that $\bar{y}^{\mathrm{FT}} / \bar{y}^{\mathrm{BT}}=1.29$. These numbers are reasonably close to those in Table 4 , in particular they are consistent with much larger efficiency gains associated with free trade in goods. If anything, these gains are slightly underestimated. ${ }^{28}$

The second step is to use this simple setting to try to predict the effect of transportation costs on $\bar{y}^{\mathrm{FT}} / \bar{y}^{\mathrm{BT}}$. Assume that the transportation costs are of the "iceberg cost" type, so that a fraction $\tau_{c}$ of every traded consumption good, and a fraction $\tau_{i}$ of every traded investment good, are simply lost. For concreteness, assume these costs are incurred by the importer of the good.

Let $p^{*}$ and $r^{*}$ be the prices that would be prevail in this new equilibrium, and denote by $G$ the unconditional distribution of $\theta$. There will be three types of countries in the world economy:

1. Countries specializing in the production of investment goods, for whom $\theta<p^{*}\left(1-\tau_{i}\right)$, and that produce $y_{i}^{*}=\left(\frac{p^{*}\left(1-\tau_{i}\right)}{\theta} z\right)^{1 /(1-\alpha)}\left(\frac{\alpha}{p^{*}\left(1-\tau_{i}\right)\left(r^{*}+\delta\right)}\right)^{\alpha /(1-\alpha)}$. Let $\mu_{i}=G\left(p^{*}\left(1-\tau_{i}\right)\right)$ denote the measure of these countries.

2. Countries specializing in the production of consumption goods, for whom $\theta>p^{*} /\left(1-\tau_{c}\right)$, and that produce $y_{c}^{*}=z^{1 /(1-\alpha)}\left(\frac{\alpha\left(1-\tau_{c}\right)}{p^{*}\left(r^{*}+\delta\right)}\right)^{\alpha /(1-\alpha)}$. Let $\mu_{c}=1-G\left(p^{*} /\left(1-\tau_{c}\right)\right)$ denote the measure of these countries.

3. Countries producing both goods, and not engaging in intratemporal trade, for whom $\theta \in$ $\left[p^{*}\left(1-\tau_{i}\right), p^{*} /\left(1-\tau_{c}\right)\right]$, and that produce $y_{c i}^{*}=z^{1 /(1-\alpha)}\left(\frac{\alpha}{\theta\left(r^{*}+\delta\right)}\right)^{\alpha /(1-\alpha)}$. These countries will be in measure $1-\mu_{i}-\mu_{c}$.

World output in this scenario will be given by $\bar{y}^{*}=\mu_{i} \bar{y}_{i}^{*}+\mu_{c} \bar{y}_{c}^{*}+\left(1-\mu_{i}-\mu_{c}\right) \bar{y}_{c i}^{*}$, where the $\bar{y}$ 's are computed by integrating over the appropriate productivity ranges.

The goal is to compute $\bar{y}^{*} / \bar{y}^{\mathrm{BT}}$ for a range of transportation cost values, and to see whether it differs a lot from $\bar{y}^{\mathrm{FT}} / \bar{y}^{\mathrm{BT}}$. To do so, one needs to assign values to $p^{*}$ and $r^{*}$. I will set $p^{*}=p$ and $r^{*}=r^{\mathrm{FT}}$, which should provide a good approximation for small enough transportation cost values. Clearly, in the full model, these prices would change with the amount of transportation costs. One should view this as a simple partial equilibrium analysis, which is able to capture the direct effect of transportation costs on specialization and aggregate productivity, but not the indirect effect through world prices.

I consider two scenarios for transportation costs: (i) $\tau_{c}=\tau>\tau_{i}=0$, costs to trading consumption goods only; and (ii) $\tau_{c}=\tau_{i}=\tau$, uniform costs to trading both consumption and investment goods. One drawback of case (i) is that, as $\tau$ increases, less and less countries produce investment goods, and one should observe a rise in $p^{*}$. Instead, $p^{*}$ is in fact held constant. In other words,

\footnotetext{
${ }^{28}$ Note that the figure for $\bar{y}^{\mathrm{NT}} / \bar{y}^{\mathrm{BT}}$ may be viewed as an upper bound for the potential gains of financial market liberalization, since the underlying expression for $k^{\mathrm{BT}} / y^{\mathrm{BT}}$ assumes all countries are unconstrained. In fact it implies an efficiency loss of going from BT to NT of 7 percent, which is indeed higher than that reported in Table 4.
} 
one would expect the efficiency gains to decrease with $\tau$ faster than case (i) implies. Case (ii), on the other hand, produces an effect that mimics the increase in $p^{*}$. However, the amount of transportation costs is presumably too high, since they apply symmetrically to both goods. One would expect the efficiency gains to decrease with $\tau$ more slowly than what is implied by case (ii).

Figure 6 represents the effect on efficiency gains of having transportation costs from 0 percent up to 50 percent of the relative investment price at the origin. This figure suggests that as long as transportation costs stay below about $1 / 3$ of the price at the origin, liberalizing trade in goods still generates higher efficiency gains than liberalizing financial markets. Probably transportation costs would have to be much larger than this in order to have a significant impact on the results. It should be emphasized, however, that this is only a simple first-pass calculation, which certainly merits a more careful investigation.

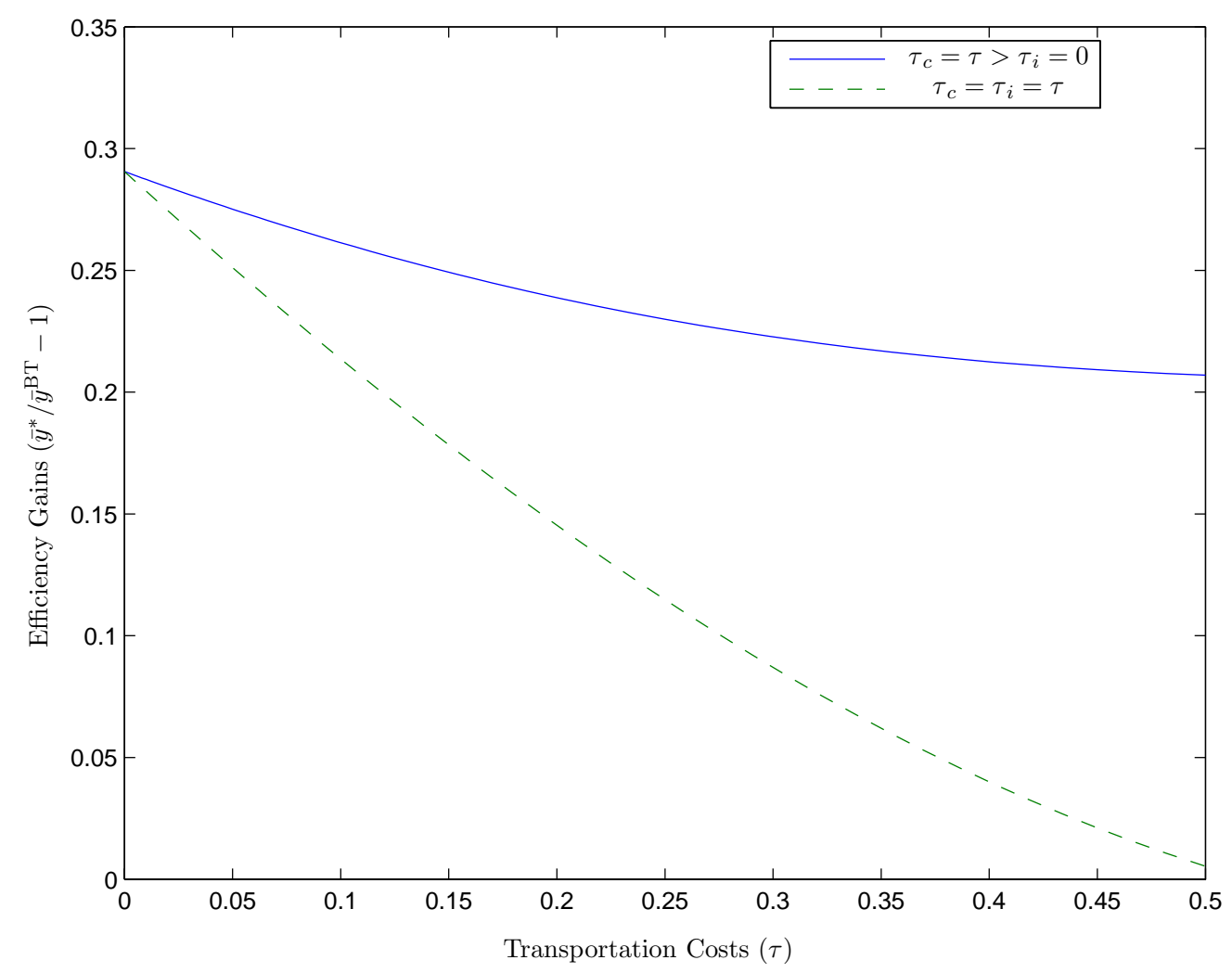

Figure 6: Effect of Transportation Costs on Steady-State Efficiency Gains

\section{References}

AiYagari, R. (1994): "Uninsured Idiosyncratic Risk and Aggregate Saving," Quarterly Journal of Economics, 109(3), 659-684. 
Aiyagari, R., And M. Gertler (1999): “Overreaction’ of Asset Prices in General Equilibrium,” Review of Economic Dynamics, 2(1), 3-35.

Backus, D. K., P. J. Kehoe, and F. E. Kydland (1992): "International Real Business Cycles," Journal of Political Economy, 100(4), 745-775.

Baxter, M., And M. J. Crucini (1995): "Business Cycles and the Asset Structure of Foreign Trade," International Economic Review, 36(4), 821-854.

Castro, R. (2004): "Economic Development and Growth in the World Economy," Review of Economic Dynamics, forthcoming.

Chari, V. V., P. J. Kehoe, and E. R. McGrattan (1997): "The Poverty of Nations: A Quantitative Exploration," Research Department Staff Report 204, Federal Reserve Bank of Minneapolis.

Clarida, R. H. (1990): "International Lending and Borrowing in a Stochastic, Stationary Equilibrium," International Economic Review, 31(3), 543-558.

Cole, H. L., and M. Obstfeld (1991): "Commodity Trade and International Risksharing: how much do financial markets matter?," Journal of Monetary Economics, 28(3), 3-24.

De Long, B., And L. H. Summers (1991): "Equipment Investment and Economic Growth," Quarterly Journal of Economics, 106(2), 445-502.

Eaton, J., And S. Kortum (2001): "Trade in Capital Goods," European Economic Review, 45(7), 1121-1339.

Frankel, J. A., and D. Romer (1999): "Does Trade Cause Growth?," American Economic Review, 89(3), 379-399.

Gollin, D. (2002): “Getting Income Shares Right: Self Employment, Unincorporated Enterprise, and the Cobb-Douglas Hypothesis," Journal of Political Economy, 110(2), 458-474.

Greenwood, J., Z. Hercowitz, and P. Krusell (1997): "Macroeconomic implications of investment-specific technological change," American Economic Review, 87(3), 342-362.

Hamilton, J. D. (1994): Time Series Analysis. Princeton University Press, Princeton, NJ.

Heston, A., L. Summers, and B. Aten (2002): "Penn World Table Version 6.1," Discussion paper, Center for International Comparisons at the University of Pennsylvania (CICUP), Philadelphia, PA. 
Hsien, C.-T., and P. J. Klenow (2003): "Relative Prices and Relative Prosperity," Working paper 9701, National Bureau of Economic Research.

Huggett, M. (1993): "The Risk-Free Rate in Heterogeneous-Agent Incomplete-Insurance Economies," Journal of Economic Dynamics and Control, 17(5-6), 953-969.

Jones, C. I. (1994): "Economic Growth and the Relative Price of Capital," Journal of Monetary Economics, 34(3), 359-382.

JudD, K. (1998): Numerical Methods in Economics. MIT Press, Cambridge, MA.

King, R. G., And S. Rebelo (2000): "Resuscitating Real Business Cycles," in Handbook of Macroeconomics, ed. by J. Taylor, and M. Woodford, vol. 1B, chap. 14, pp. 927-1007. Elsevier Science, North-Holland, Amsterdam, New York and Oxford.

Lucas, JR., R. E. (1987): Models of Business Cycles, Yrjö Jahnsson Lectures. Basil Blackwell, Ocford.

Mankiw, N. G., D. Romer, and D. N. Weil (1992): "A Contribution to the Empirics of Economic Growth," Quarterly Journal of Economics, 107(2), 407-437.

Parente, S. L., and E. C. Prescott (1993): "Changes in the Wealth of Nations," Federal Reserve Bank of Minneapolis Quarterly Review, 17(2), 1216-1233.

(2002): Barriers to Riches, The Walras-Pareto Lectures. MIT Press, Cambridge, MA.

PAvCNIK, N. (2002): "Trade Liberalization, Exit, and Productivity Improvements: Evidence from Chilean Plants," Review of Economic Studies, 69(1), 245-276.

Restuccia, D., and C. Urrutia (2001): "Relative Prices and Investment Rates," Journal of Monetary Economics, 47(1), 93-121.

Rodríguez, F., And D. Rodrik (2000): "Trade Policy and Economic Growth: A Skeptic's Guide to the Cross-National Evidence," in NBER Macroeconomics Annual 2000, ed. by J. Rotemberg, and M. Woodford. MIT Press, Cambridge, MA.

Stokey, N. L., R. E. Lucas, JR., and E. C. Prescott (1989): Recursive Methods in Economic Dynamics. Harvard University Press, Cambridge, MA.

Summers, L. H. (2000): "International Financial Crises: Causes, Prevention and Cures," American Economic Review Papers and Proceedings, 90(2), 1-16. 